\title{
Optimization of Kiloampere Peltier Current Lead Using Orthogonal Experimental Design Method
}

\author{
Linying Liu ${ }^{1}$, Shengnan Zou ${ }^{1}{ }^{\mathbb{C}}$, Shutong Deng ${ }^{1, *}$, Lingfeng Lai ${ }^{2}$ and Chen Gu ${ }^{3}$ \\ 1 Quanzhou Institute of Equipment Manufacturing, Haixi Institudes, Chinese Academy of Siences, \\ Quanzhou 362200, China; liulinying@fjirsm.ac.cn (L.L.); shengnan.zou@fjirsm.ac.cn (S.Z.) \\ 2 Beijing East-Forces Superconducting Technology Co., Ltd, Beijing 100085, China; lingfenglai@gmail.com \\ 3 Teaching Center of Experimental Physics, Tsinghua University, Beijing 100084, China; \\ guchen@tsinghua.edu.cn \\ * Correspondence: shutong.deng@fjirsm.ac.cn
}

check for updates

Citation: Liu, L.; Zou, S.; Deng, S.; Lai, L.; Gu, C. Optimization of Kiloampere Peltier Current Lead Using Orthogonal Experimental Design Method. Electronics 2021, 10, 1054. https://doi.org/10.3390/ electronics10091054

Academic Editor: Fernando A. Silva

Received: 25 March 2021

Accepted: 23 April 2021

Published: 29 April 2021

Publisher's Note: MDPI stays neutral with regard to jurisdictional claims in published maps and institutional affiliations.

Copyright: (c) 2021 by the authors. Licensee MDPI, Basel, Switzerland. This article is an open access article distributed under the terms and conditions of the Creative Commons Attribution (CC BY) license (https:/ / creativecommons.org/licenses/by/ $4.0 /)$.

\begin{abstract}
Reducing heat leakage is crucial for the development of practical superconducting devices. In this work, orthogonal experimental design method is first used to optimize the design of hundredampere and kiloampere Peltier current leads (PCLs). Geometry and arrangement of Peltier materials and conductive materials of the current lead are analyzed. Through our simulation, we find that the coupling effect between the radius of $\mathrm{Bi}_{2} \mathrm{Te}_{3}\left(r_{2}\right)$ and the length of $\mathrm{Bi}_{2} \mathrm{Te}_{3}\left(L_{2}\right)$ has the greatest effect on the heat leakage of PCLs at the cold end for both PCLs. Furthermore, numerical simulations suggest that the lowest heat leakage at the cold end (approximately $30.0 \mathrm{~W} / \mathrm{kA}$ ) is at the same level for both hundred-ampere and kiloampere PCLs. If taking the heat dissipation area at the hot end into account, multiterminal solutions are better solutions for kiloampere current leads.
\end{abstract}

Keywords: PCLs; heat leakage; orthogonal experimental

\section{Introduction}

Recently, great progress has been made in the development of high-temperature superconducting (HTS) applications. Many demonstrative projects have been tested in grids, such as HTS cables [1-7], superconducting fault current limiters [8-11], and superconducting maglevs [12-15]. Concept design and demo tests of superconducting electrical machines have proved the potential of HTS electrical machines in electrical aircraft and wind turbines [16-23]. For any HTS electrical power application, a strong current has to be fed by a current lead bridging between room and cryogenic temperatures. Inevitably, heat is transferred via the current lead into the HTS applications contained in the low temperature: at the same time, the resistive current lead produces Joule heat and contributes extra heat. The heat from the current lead is the main loss of the short line HTS applications and becomes a thermal load burden to the cryogenic system. Peltier effect, also known as the thermoelectric effect, can be used to reduce the heat load at the low-temperature side by transferring heat reversely to the room temperature.

Because the PCLs have a large temperature difference between both ends, the thermoelectric material $\left(\mathrm{Bi}_{2} \mathrm{Te}_{3}\right)$ and copper have the characteristic parameters that vary with the temperature. At first, pioneer researcher Yamaguchi proposed a one-dimensional iterative method [24,25], assuming that thermoelectric parameters are not affected by temperature. Subsequently, in order to transform the heat conduction equation into a linear differential equation, Widemann-Franz law was introduced and an approximate analytic solution was obtained [26]. Later, Jeong limited the thermoelectric parameter independent of temperature to the Seebeck coefficient and obtained a more accurate analytical solution [27]. On this basis, some groups have further considered the influence of the cooling mode [28,29], the thermoelectric performance [30], the structure, and the higher current capacity of PCLs on the heat leakage [31-33]. 
All the above studies had the goal of obtaining the minimum heat leakage of PCLs, so optimal $\mathrm{Bi}_{2} \mathrm{Te}_{3}(\mathrm{~L} / \mathrm{A}) \mathrm{p}$ and copper $(\mathrm{L} / \mathrm{A}) \mathrm{c}$ ratios should be required ( $\mathrm{L}$ is the length and $\mathrm{A}$ is the cross-sectional area). Though the one-dimensional iterative method and the analytic solution can estimate the optimal ratios (L/A) well, they have great limitations in solving nonlinear problems in practice. Fortunately, some researchers have used multiphysics software COMSOL [34] to deal with nonlinear problems. However, the emerging COMSOL simulation solutions need to blindly select an optimal ratio of L/A from numerous values.

Hence, through a COMSOL two-dimensional asymmetrical model of PCL finite element simulation, this study firstly uses the orthogonal experiment to scientifically choose the parameters that have a great influence on the heat leakage at the cold end from the dimension parameters and their coupling effect parameters. Based on these more influential parameters, the optimization range is narrowed. Then, through step by step optimization, a set of optimal parameter sizes to obtain minimum heat leakage of PCLs is found.

This work is characterized by its innovation of using the orthogonal experiment design method to solve the key difficulty of HTS current lead optimization: many parameters and their coupling factors determine the heat leakage delicately with both thermal and electrical effects. There is a heavy workload in the optimization of the results from such a large parametric matrix, and it is difficult to find global optimal solutions. The method developed in this work significantly reduces the number of simulations or experimental cases during the optimization process, and adequate optimal solutions can be found for different applications. The method developed in this work can be used not only to optimize the regular PCLs described in this work but also to optimize arbitrarily shaped PCLs, which may have wide application in the future.

\section{Model and Analysis Method}

\subsection{Model}

Figure 1 shows the structure of a conduction-cooled PCL. $\mathrm{Bi}_{2} \mathrm{Te}_{3}$ and copper blocks compose a model of sandwich configuration, called the Peltier element (PE). PEs are put at the warm terminals of copper leads. As the dimension parameters of the copper blocks will lead to a complex optimization process, to simplify, this work uses the structure of PCLs as shown in Figure 2. The optimized dimensional parameters used were as follows: A, the copper leads radius $\left(r_{1}\right)$; B, the length of warm end copper leads $\left(L_{1}\right)$; , the length of cold end copper leads $\left(L_{3}\right)$; and $\mathrm{D}$ and $\mathrm{E}$, the radius and length of $\mathrm{Bi}_{2} \mathrm{Te}_{3}\left(r_{2}\right.$ and $\left.L_{2}\right)$, respectively.

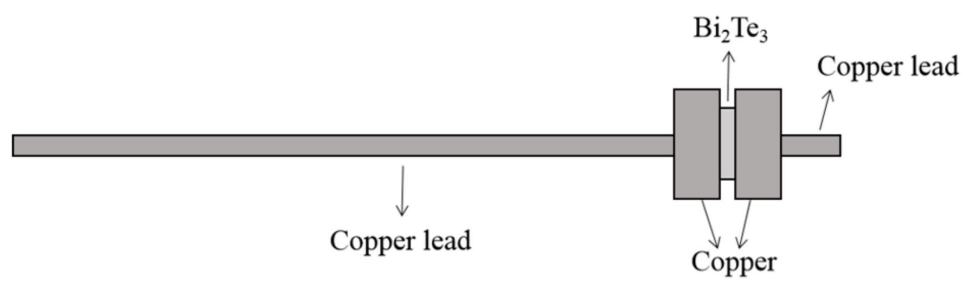

Figure 1. Schematic view of a PCL.

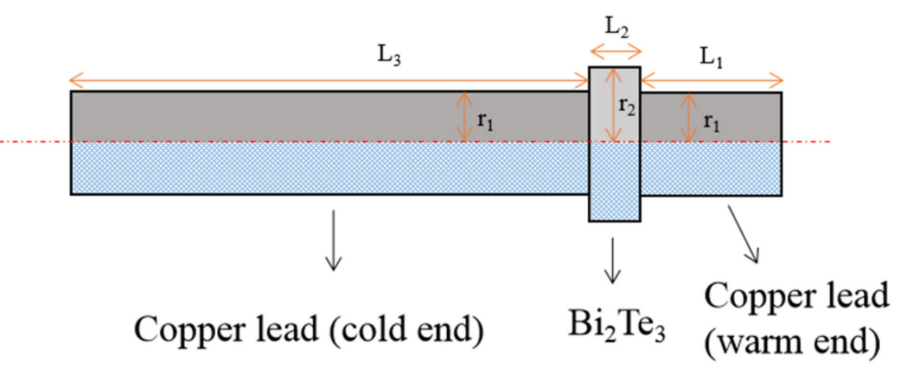

Figure 2. Schematic view of a simplified PCL. 
In this paper, the finite element method is used to analyze the heat transfer in PCLs. A two-dimensional asymmetrical thermoelectricity-coupled model is established by COMSOL 5.3 [34] with the temperature characteristics of material parameters reported in [28,31-33]. Thermal (electric) contact resistance and thermal radiation are ignored. The PCL operates in a vacuum chamber with the designed current 120 or $1200 \mathrm{~A}$. The roomtemperature terminal is set as constant temperature $(300 \mathrm{~K})$. At the cold terminal, as the PCL extends into the liquid nitrogen pipeline, we set the temperature as $77 \mathrm{~K}$. Taking the minimum heat leakage of PCL as the optimization target, the heat leakage of PCL is calculated by the solid heat transfer module of COMSOL simulation software. As the cost of the heat dissipation at the cold end is much larger than at the warm terminals, we only consider the minimum heat leakage at the cold end as the optimization target.

\subsection{Optimization Procedure}

Figure 3 is the flow chart of using orthogonal experiment to optimize the PCLs to achieve the minimum heat leakage. For this purpose, the optimization should experience two major steps: one is the orthogonal experiment, the other is the global optimization of the PCLs. Orthogonal experimental design is a design method to arrange and analyze multifactor experiments by using an orthogonal table [35]. It is carried out by selecting some representative factors among all experimental factors. Through the analysis of these experimental results, the overall situation of the test is understood, and the optimal factor is determined. The basic characteristic of orthogonal experimental design is to replace the comprehensive test with a partial test and to understand the situation of the comprehensive test through the analysis of partial test results. More information about orthogonal experimental design can be found in Ref. [35].

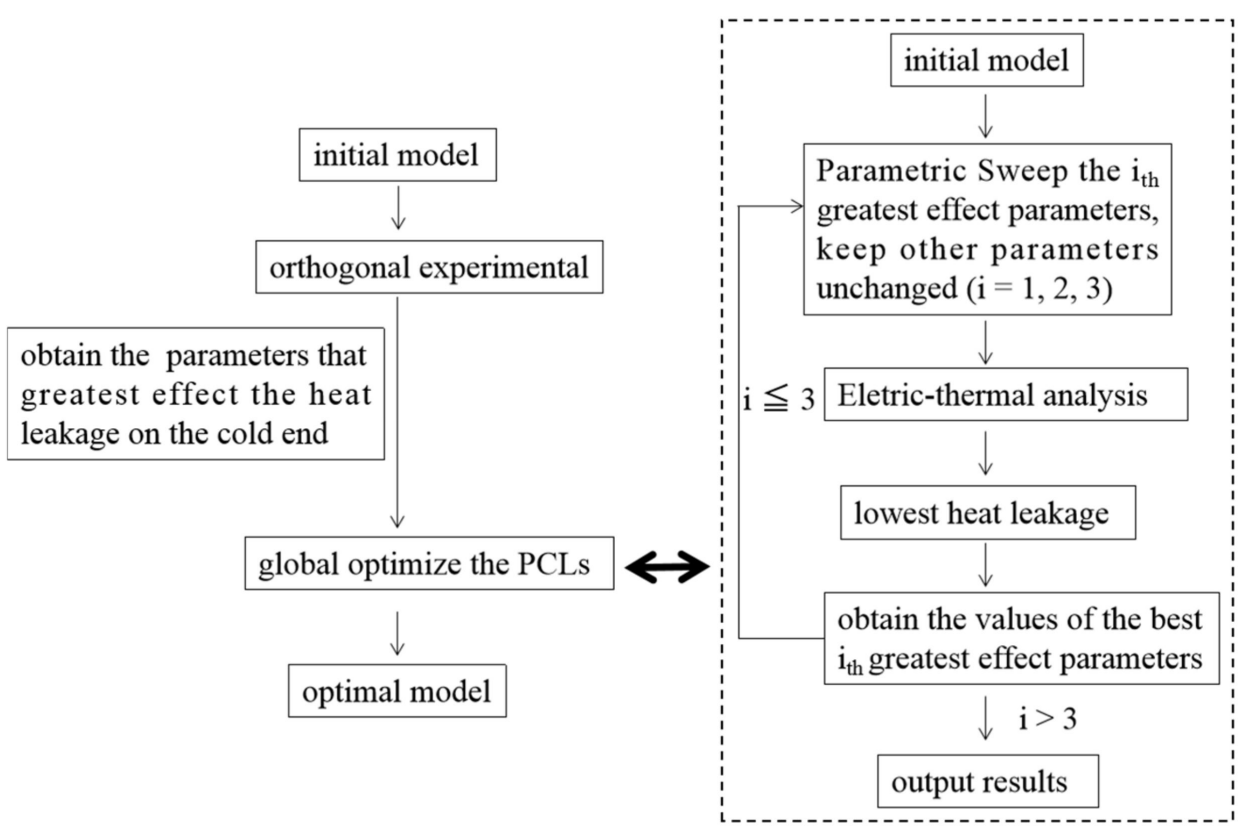

Figure 3. Global optimization procedure.

The specific optimization steps are as follows (Figure 3): First, orthogonal experiment is completed for the initial model. Thus, we obtain the parameters that have the greatest effect the heat leakage at the cold end. Then, we use these greatest effect factors to globally optimize the PCLs. The global optimization process is as follows: Based on the initial model, we choose the first three greatest effect parameters for a parametric sweep, keeping other parameters unchanged. Via the electric-thermal analysis, we can obtain the lowest heat leakage among the parametric sweep results. The corresponding value of the $i_{\text {th }}$ $(i=1,2,3)$ greatest effect parameter is the best one, so we change them and fix them in the 
next iteration. Then, we parametric sweep the second/third greatest effect parameters of the model and obtain the global lowest heat leakage. As with outputting a group of best dimensional parameters, the optimal model is achieved.

\section{Results and Discussions}

\subsection{Results of 120 A Peltier Current Lead Optimization \\ 3.1.1. Orthogonal Experimental Design for 120 A PCLs}

For the chosen five optimized dimensional parameters, our orthogonal experiment considers their minimum and maximum values, as shown in Table 1. The principle for data selection is based on the previous literature [28,31-33] and our simulation experience. As there are five parameters, adding the ten parameters that describe the coupling effect between them, we design an $\mathrm{L}_{16}\left(2^{15}\right)$ orthogonal experimental table to achieve our goal. Here, the " $L$ " represents the orthogonal table and the number " 16 " in subscript represents 16 lines, meaning the experiment with this orthogonal table contains 16 treatments. The base " 2 " in parentheses indicates the horizontal number of parameters. The exponent " 15 " in the parentheses indicates that there are 15 columns, and a maximum of 15 2-level parameters can be arranged using this orthogonal table. More information about orthogonal experimental design can be seen in Appendix A.1.

Table 1. Orthogonal experimental design for 120 A PCLs.

\begin{tabular}{ccccc}
\hline \multirow{2}{*}{ Symbol } & \multirow{2}{*}{ Quantity } & \multicolumn{2}{c}{ Values $(\mathbf{m m})$} & \multirow{2}{*}{$\begin{array}{c}\text { Column } \\
\text { Number }\end{array}$} \\
\cline { 3 - 4 } & & Level 1 & Level 2 & \\
\hline A: $r_{1}$ & Radius of copper leads & 3.0 & 30.0 & 1 \\
B: $L_{1}$ & Length of warm end copper leads & 10.0 & 300.0 & 2 \\
C: $L_{3}$ & Length of cold end copper leads & 100.0 & 1500.0 & 4 \\
D: $r_{2}$ & Radius of $\mathrm{Bi}_{2} \mathrm{Te}_{3}$ & 1.0 & 30.0 & 8 \\
E: $L_{2}$ & Length of $\mathrm{Bi}_{2} \mathrm{Te}_{3}$ & 1.0 & 30.0 & 15 \\
\hline
\end{tabular}

\subsubsection{Orthogonal Experimental Results of 120 A PCLs}

Table 2 is the orthogonal experimental results. The sample range indicates the influence weight of the corresponding parameters on the heat leakage of PCLs at the cold end. The larger the values, the greater the effect. From the sample range in Table 2, we can find that the most important factors affecting the heat leakage of PCLs at the cold end are $\mathrm{D} \times \mathrm{E}, \mathrm{B} \times \mathrm{C}$, and $\mathrm{A}$. Here, the $\mathrm{D} \times \mathrm{E}$ and $\mathrm{B} \times \mathrm{C}$ indicate the parameters of coupling effect between $D$ and $E$ and between $B$ and $C$, respectively. Furthermore, we find that parameter $B$ (length of warm end copper leads) has little effect on the heat leakage at the cold end.

Moreover, the mean value 1 and mean value 2 indicates the influence of each level of parameters on the experimental indexes. As our goal is to achieve the minimum heat leakage of PCLs at the cold end, the smaller mean values correspond to better levels. Hence, for parameter A (copper leads radius $\left.r_{1}\right)$, the level $1\left(r_{1}=3.0 \mathrm{~mm}\right)$ is better. Similarly, we obtain better values for $L_{1}=10.0 \mathrm{~mm}, L_{3}=1500.0 \mathrm{~mm}, r_{2}=30.0 \mathrm{~mm}$, and $L_{2}=1.0 \mathrm{~mm}$. We set these values as the initial values.

\subsubsection{Global Optimization of the 120 A PCLs}

Based on the orthogonal experimental results presented in the previous subsection, we know the parameters that have the greatest effect on the heat leakage at the cold end are $\mathrm{D} \times \mathrm{E}, \mathrm{B} \times \mathrm{C}$, and $\mathrm{A}$. Thus, we first optimize the parameter of the interaction between $\mathrm{D}$ (radius of $\mathrm{Bi}_{2} \mathrm{Te}_{3}, r_{2}$ ) and $\mathrm{E}$ (length of $\mathrm{Bi}_{2} \mathrm{Te}_{3}, L_{2}$ ) to reveal their coupling influence on the heat leakage at the cold end (as shown in Figure 4), keeping the other parameters unchanged (radius of copper leads $r_{1}=3.0 \mathrm{~mm}$, length of warm end copper leads $L_{1}=10.0 \mathrm{~mm}$, length of cold end copper leads $L_{3}=1500.0 \mathrm{~mm}$ ). 
Table 2. Orthogonal experimental results of 120 A PCLs.

\begin{tabular}{|c|c|c|c|c|c|c|c|c|c|c|c|c|c|c|c|}
\hline $\begin{array}{l}\text { Column } \\
\text { Number }\end{array}$ & 1 & 2 & 3 & 4 & 5 & 6 & 7 & 8 & 9 & 10 & 11 & 12 & 13 & 14 & 15 \\
\hline Parameters & $\begin{array}{c}\text { A: } \\
\text { Copper } \\
\text { Leads } \\
\text { Radius } \\
\left(r_{1} / \mathrm{mm}\right)\end{array}$ & $\begin{array}{l}\text { B: Length of } \\
\text { Warm end } \\
\text { Copper } \\
\text { Leads } \\
\left(L_{1} / \mathrm{mm}\right)\end{array}$ & $\mathbf{A} \times \mathbf{B}$ & $\begin{array}{l}\text { C: Length } \\
\text { of Cold } \\
\text { End } \\
\text { Copper } \\
\text { Leads } \\
\left(L_{3} / \mathrm{mm}\right)\end{array}$ & $\mathbf{A} \times \mathbf{C}$ & $\mathbf{B} \times \mathbf{C}$ & $\mathbf{D} \times \mathbf{E}$ & $\begin{array}{c}\text { D: } \\
\text { Radius } \\
\text { of } \\
\mathrm{Bi}_{2} \mathrm{Te}_{3} \\
\left(r_{2} / \mathrm{mm}\right)\end{array}$ & $\underset{\mathbf{D}}{\mathbf{A} \times}$ & $\mathbf{B} \times \mathbf{D}$ & $\mathbf{C} \times \mathbf{E}$ & $\mathbf{C} \times \mathbf{D}$ & $\mathbf{B} \times \mathbf{E}$ & $\mathbf{A} \times \mathbf{E}$ & $\begin{array}{c}\mathrm{E}: \\
\text { Length } \\
\text { of } \\
\mathrm{Bi}_{2} \mathrm{Te}_{3} \\
\left(L_{2} / \mathrm{mm}\right)\end{array}$ \\
\hline $\begin{array}{c}\text { Mean } \\
\text { value } 1\end{array}$ & 966.0 & $1736.5^{1}$ & 1125.0 & 2143.2 & 1524.1 & 2379.2 & 223.7 & 2326.7 & 1801.2 & 1169.4 & 1738.9 & 1591.0 & 2166.4 & 1552.0 & 1002.1 \\
\hline $\begin{array}{c}\text { Mean } \\
\text { value } 2\end{array}$ & 2361.2 & 1591.6 & 2202.3 & 1184.0 & 1803.1 & 948.0 & 3103.5 & 1000.5 & 1526.0 & 2157.8 & 1588.3 & 1736.2 & 1160.8 & 1775.1 & 2325.1 \\
\hline $\begin{array}{c}\text { Sample } \\
\text { range }\end{array}$ & 1395.3 & 143.9 & 1077.3 & 959.2 & 279.1 & 1431.2 & 2879.8 & 1326.2 & 275.3 & 988.5 & 150.6 & 145.3 & 1005.6 & 223.2 & 1323.1 \\
\hline
\end{tabular}

${ }^{1}$ While the orthogonal experimental results indicate the better initial value for $L_{1}$ is $300.0 \mathrm{~mm}$, we choose $L_{1}=10.0 \mathrm{~mm}$ as the initial value. On the one hand, there exists a small difference between the Mean values 1 and 2 for $L_{1}$ in Table 2, but this difference provides insufficient support to choose which one is better. On the other hand, through the parametric sweep iteration, we find that a shorter length of warm end copper leads is better. In addition, the orthogonal experimental results indicate that the parameter $\mathrm{B}\left(L_{1}\right)$ has little effect on the heat leakage at the cold end. Based on these considerations, we choose $L_{1}=10.0 \mathrm{~mm}$ as the initial value.
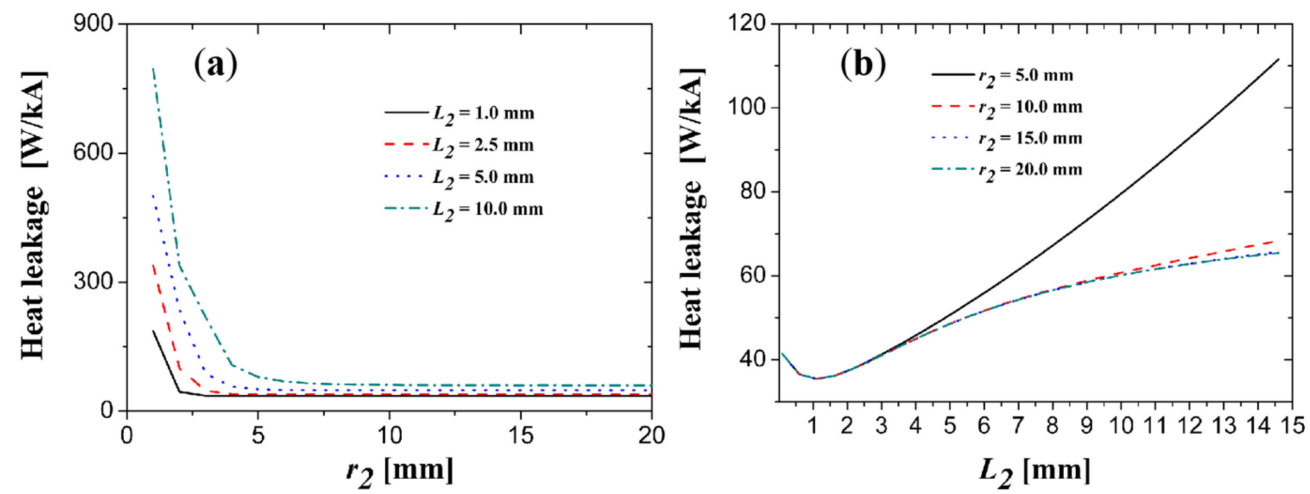

Figure 4. The coupling influence between D $\left(r_{2}\right)$ and $\mathrm{E}\left(L_{2}\right)$ on the cold end heat leakage of PCLs. (a) The heat leakage vary with $\mathrm{D}\left(r_{2}\right) ;(\mathbf{b})$ The heat leakage vary with $\mathrm{E}\left(L_{2}\right)$.

It can be seen in Figure $4 \mathrm{a}$ that using a smaller $L_{2}$ achieves a smaller heat leakage value (black curve). Moreover, the value of $r_{2}$ (radius of $\mathrm{Bi}_{2} \mathrm{Te}_{3}$ ) has a large influence on the heat leakage of PCLs. When the value of $r_{2}$ is larger than a certain value (such as $10.0 \mathrm{~mm}$ ), the heat leakage curve becomes stable at low values. In addition, from Figure $4 \mathrm{~b}$, we find that the heat leakage curves for $r_{2}=10.0 \mathrm{~mm}, 15.0 \mathrm{~mm}$, and $20.0 \mathrm{~mm}$ are similar. Hence, we set the value of parameter D to $r_{2}=10.0 \mathrm{~mm}$. Based on this setting, we obtain the lowest heat leakage of $35.49 \mathrm{~W} / \mathrm{kA}$ at the cold end of PCLs when $L_{2}=1.0 \mathrm{~mm}$. We set $r_{2}$ equal to $10.0 \mathrm{~mm}$ and $L_{2}$ equal $1.0 \mathrm{~mm}$ and fix them in the next iteration.

Then, we optimize the parameter of the interaction between $\mathrm{B}\left(L_{1}\right)$ and $\mathrm{C}\left(L_{3}\right)$ to reveal their coupling influence on the heat leakage at the cold end (as shown in Figure 5), keeping the other parameters unchanged $\left(r_{1}=3.0 \mathrm{~mm}, r_{2}=10.0 \mathrm{~mm}, L_{2}=1.0 \mathrm{~mm}\right)$. As shown in Figure 5a, the optimal value of cold end copper leads $\left(L_{3}\right)$ is some intermediate value, which is confirmed by Figure $5 b$. As shown in Figure $5 b$, with the increasing in the length of cold end copper leads $\left(L_{3}\right)$, the heat leakage curve is decreased first and then increased. Hence, we have best values for B and C $\left(L_{1}=10.0 \mathrm{~mm}, L_{3}=700.0 \mathrm{~mm}\right)$. Under these optimization parameters, the lowest heat leakage at the cold end of PCLs is $30.1 \mathrm{~W} / \mathrm{kA}$. 

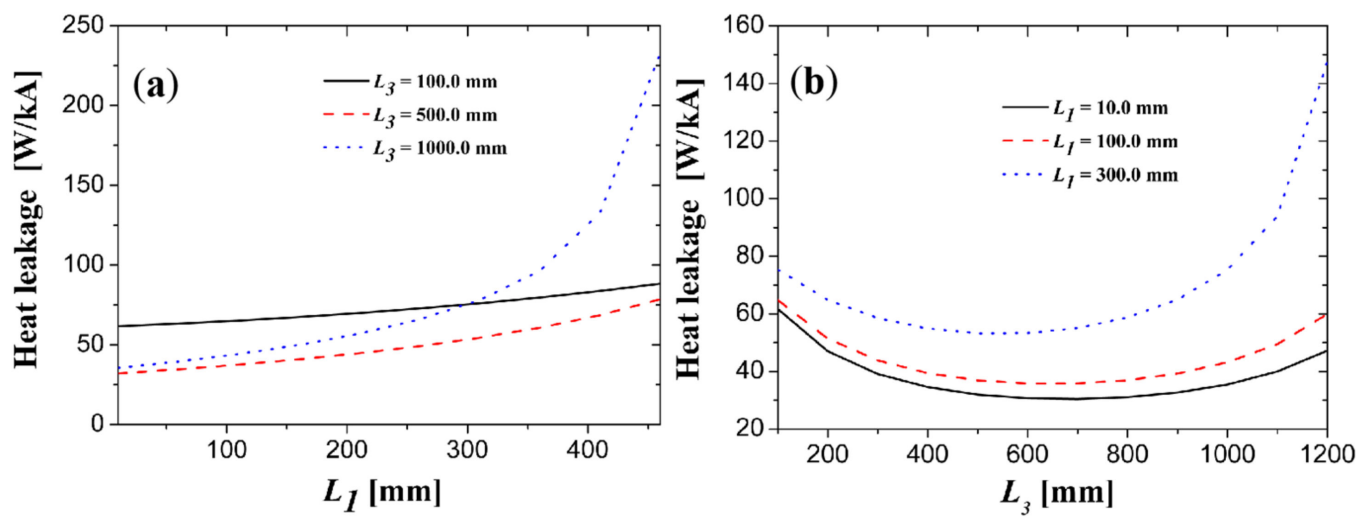

Figure 5. The coupling influence between $\mathrm{B}\left(L_{1}\right)$ and $\mathrm{C}\left(L_{3}\right)$ on the cold end heat leakage of PCLs. (a) The heat leakage vary with $\mathrm{B}\left(L_{1}\right)$; (b)The heat leakage vary with $\mathrm{C}\left(L_{3}\right)$.

Finally, we optimize the parameter A (radius of the copper leads $r_{1}$ ), keeping the other parameters unchanged $\left(L_{1}=10.0 \mathrm{~mm}, L_{3}=700.0 \mathrm{~mm}, r_{2}=10.0 \mathrm{~mm}, L_{2}=1.0 \mathrm{~mm}\right)$. Figure 6 illustrates the effect of $r_{1}$ on the heat leakage of PCLs. Here, we obtain the best value for $r_{1}=3 \mathrm{~mm}$ and achieve an optimized structure of PCLs with the lowest heat leakage of $30.1 \mathrm{~W} / \mathrm{kA}$.

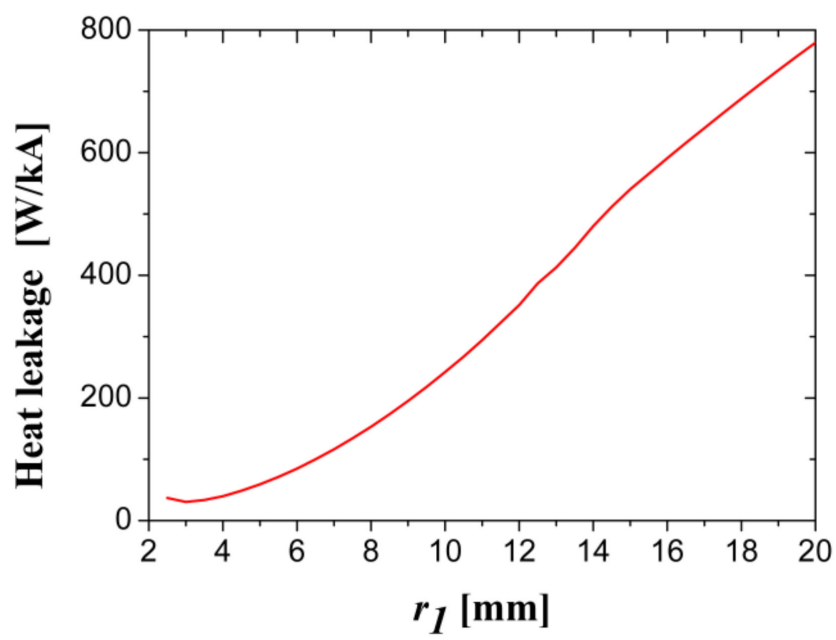

Figure 6. The effect of radius of the copper leads $r_{1}$ on the cold end heat leakage of PCLs.

Then, we change the initial values for different dimensional parameters slightly, and through parametric sweep iteration, we obtain another two sets of optimal parameter sizes corresponding to a minimum heat leakage of PCLs, as shown in Table 3 (the details of the iteration progress are listed in Appendix A.2). Obviously, compared with the traditional copper current leads, the reduction rate of heat leakage at the cold end of PCLs exceeds $30 \%$. That shows a huge advantage in saving energy for PCLs. 
Table 3. Three sets of optimal parameters for 120 A PCLs.

\begin{tabular}{ccccc}
\hline \multirow{2}{*}{ Symbol } & \multirow{2}{*}{ Quantity } & \multicolumn{2}{c}{ Optimized Parameters } \\
\cline { 3 - 5 } & & Case 1 & Case 2 & Case 3 \\
\hline $\mathrm{A}: r_{1}$ & Radius of copper leads $(\mathrm{mm})$ & 3.0 & 4.0 & 5.5 \\
$\mathrm{~B}: L_{1}$ & Length of warm end copper leads $(\mathrm{mm})$ & 10.0 & 10.0 & 10.0 \\
$\mathrm{C}: L_{3}$ & Length of cold end copper leads $(\mathrm{mm})$ & 700.0 & 1100.0 & 1900.0 \\
$\mathrm{D}: r_{2}$ & Radius of $\mathrm{Bi}_{2} \mathrm{Te}_{3}(\mathrm{~mm})$ & 10.0 & 10.0 & 10.0 \\
$\mathrm{E}: L_{2}$ & Length of $\mathrm{Bi}_{2} \mathrm{Te}_{3}(\mathrm{~mm})$ & 1.0 & 3.5 & 7.0 \\
& Lowest heat leakage $(\mathrm{W} / \mathrm{kA})$ & 30.1 & 29.7 & 29.8 \\
& Heat leakage with pure copper $(\mathrm{W} / \mathrm{kA})$ & 43.2 & 45.6 & 47.9 \\
& Reduction rate of cold end heat leakage & $30.4 \%$ & $34.8 \%$ & $37.7 \%$ \\
\hline
\end{tabular}

From Table 3, we find that the optimal value for $r_{2}$ in the three cases is $10.0 \mathrm{~mm}$. However, the value of $r_{2}$ (radius of $\mathrm{Bi}_{2} \mathrm{Te}_{3}$ ) has a great influence on the heat leakage of PCLs. When the value of $r_{2}$ is larger than a certain value (such as $10.0 \mathrm{~mm}$ ), the heat leakage curve becomes stable at low values. Moreover, we find that the optimal value for $L_{1}$ in the three cases is $10.0 \mathrm{~mm}$. On the one hand, the orthogonal experimental results show that parameter B $\left(L_{1}\right)$ has little effect on the heat leakage at the cold end. On the other hand, through the parametric sweep iteration, we find that a shorter length of the warm end copper leads is better. Hence, we set the best value for $L_{1}$ as $10.0 \mathrm{~mm}$. Based on these settings, the optimal values of $120 \mathrm{~A}$ PCLs for $L_{2}$ and $L_{3}$ are increased with the increase in the radius of copper leads $r_{1}$. In addition, the lowest heat leakage for three optimization cases is about $30.0 \mathrm{~W} / \mathrm{kA}$, which is in good agreement with previous works [28,31-33]. This indicates the method used in this work is reliable.

From these optimization processes, we find that the initial values have a great influence on the result. If change these optimal dimension parameters to the optimal ratio of $\mathrm{L} / \mathrm{A}$, there still exists a wide variety in the ratios of $(\mathrm{L} / \mathrm{A})_{\mathrm{p}}$ and $(\mathrm{L} / \mathrm{A})_{\mathrm{c}}$. That is also consistent with previous studies [28,31-33], in which the optimal ratios of L/A were in a wide range. Hence, the problem of optimization of the PCLs is a multisolution problem.

\subsection{Results of 1200 A Peltier Current Lead Optimization}

\subsubsection{Orthogonal Experimental Design for 1200 A PCLs}

Considering the multiple uses of PCLs, designing a multiterminal current lead connector for higher current applications is necessary. We set the current in the multiterminal current lead connector as 1200 A. For the 1200 A PCL optimization, we also choose two values (the minimum and the maximum) for each optimized dimensional parameter, as shown in Table 4. The principle for data selection is based on ensuring the convergence of the model, choosing a parameter value range as wide as possible. We also design an $\mathrm{L}_{16}$ $\left(2^{15}\right)$ orthogonal experimental table to achieve our goal. More information about orthogonal experimental design can be seen in Appendix A.3.

Table 4. Orthogonal experimental design for 1200 A PCLs.

\begin{tabular}{ccccc}
\hline \multirow{2}{*}{ Symbol } & Quantity & \multicolumn{2}{c}{ Values (mm) } & Column \\
& & Level 1 & Level 2 & Number \\
\hline A: $r_{1}$ & Radius of Copper leads & 10.0 & 80.0 & 1 \\
B: $L_{1}$ & Length of warm end copper leads & 10.0 & 300.0 & 2 \\
C: $L_{3}$ & Length of cold end copper leads & 100.0 & 1500.0 & 4 \\
D: $r_{2}$ & Radius of $\mathrm{Bi}_{2} \mathrm{Te}_{3}$ & 5.0 & 50.0 & 8 \\
E: $L_{2}$ & Length of $\mathrm{Bi}_{2} \mathrm{Te}_{3}$ & 1.0 & 50.0 & 15 \\
\hline
\end{tabular}

\subsubsection{Orthogonal Experimental Results of 1200 A PCLs}

Table 5 is the orthogonal experimental results. As the larger value of the sample range indicates the greater effect of the corresponding parameters on the heat leakage of PCLs 
at the cold end, we can summarize the following effect weight order: $\mathrm{D} \times \mathrm{E}, \mathrm{D}, \mathrm{E}, \mathrm{B} \times \mathrm{C}$, and $\mathrm{A}$. To some extent, it is consistent with the order $\mathrm{D} \times \mathrm{E}, \mathrm{B} \times \mathrm{C}$, and $\mathrm{A}$, which is that found in the orthogonal experimental results for the 120 A PCLs. Furthermore, for the optimization of 1200 A PCLs, parameter B (length of warm end copper leads) also has little effect on the heat leakage at the cold end. As the mean value is smaller, the corresponding level is better. For parameter A (copper leads radius $\left.r_{1}\right)$, the level $1\left(r_{1}=10.0 \mathrm{~mm}\right)$ is better. Similarly, we have better values for $L_{1}=10.0 \mathrm{~mm}, L_{3}=1500.0 \mathrm{~mm}, r_{2}=50.0 \mathrm{~mm}$, and $L_{2}$ $=1.0 \mathrm{~mm}$. The chosen levels for all these parameters are consistent with the orthogonal experimental results for 120 A PCLs. We set these values as the initial values.

Table 5. Orthogonal experimental results of 1200 A PCLs.

\begin{tabular}{|c|c|c|c|c|c|c|c|c|c|c|c|c|c|c|c|}
\hline $\begin{array}{l}\text { Column } \\
\text { Number }\end{array}$ & 1 & 2 & 3 & 4 & 5 & 6 & 7 & 8 & 9 & 10 & 11 & 12 & 13 & 14 & 15 \\
\hline Parameters & $\begin{array}{c}\text { A: } \\
\text { Copper } \\
\text { Leads } \\
\text { Radius } \\
\left(r_{1} / \mathrm{mm}\right)\end{array}$ & $\begin{array}{l}\text { B: Length of } \\
\text { Warm End } \\
\text { Copper } \\
\text { Leads } \\
\left(L_{1} / \mathrm{mm}\right)\end{array}$ & $\mathbf{A} \times \mathbf{B}$ & $\begin{array}{l}\text { C: Length } \\
\text { of Cold } \\
\text { end } \\
\text { Copper } \\
\text { Leads } \\
\left(L_{3} / \mathrm{mm}\right)\end{array}$ & $\mathbf{A} \times \mathbf{C}$ & $\mathbf{B} \times \mathbf{C}$ & $\mathbf{D} \times \mathbf{E}$ & $\begin{array}{c}\text { D: } \\
\text { Radius } \\
\text { of } \\
\mathrm{Bi}_{2} \mathrm{Te}_{3} \\
\left(r_{2} / \mathrm{mm}\right)\end{array}$ & $\underset{\mathbf{D}}{\mathbf{A} \times}$ & $\mathbf{B} \times \mathbf{D}$ & $\mathbf{C} \times \mathbf{E}$ & $\mathrm{C} \times \mathrm{D}$ & $\mathbf{B} \times \mathbf{E}$ & $\mathbf{A} \times \mathbf{E}$ & $\begin{array}{c}\mathrm{E}: \\
\text { Length } \\
\text { of } \\
\mathrm{Bi}_{2} \mathrm{Te}_{3} \\
\left(\mathrm{~L}_{2} / \mathrm{mm}\right)\end{array}$ \\
\hline $\begin{array}{c}\text { Mean } \\
\text { value } 1\end{array}$ & 726.0 & 918.8 & 746.3 & 1199.1 & 1024.4 & 1347.3 & 152.6 & 1583.1 & 962.5 & 786.1 & 920.6 & 1064.0 & 1198.5 & 1004.9 & 392.0 \\
\hline $\begin{array}{c}\text { Mean } \\
\text { value } 2\end{array}$ & 1267.8 & 1075.0 & 1247.5 & 794.7 & 969.4 & 647.5 & 1841.2 & 410.7 & 1031.3 & 1207.6 & 1073.2 & 929.8 & 795.4 & 988.9 & 1601.8 \\
\hline $\begin{array}{c}\text { Sample } \\
\text { range }\end{array}$ & 541.7 & 156.2 & 501.2 & 404.3 & 55.0 & 700.7 & 1688.7 & 1172.4 & 68.8 & 421.5 & 152.5 & 134.2 & 403.1 & 16.1 & 1209.8 \\
\hline
\end{tabular}

\subsubsection{Global Optimization of the 1200 A PCLs}

Based on the orthogonal experimental results presented in the previous subsection, we choose the first three greatest parameters to optimize. Through parametric sweep iteration, by changing the initial values for different dimensional parameters slightly, we obtain several sets of optimal parameter sizes corresponding to a minimum heat leakage of PCLs, as shown in Table 6. Obviously, compared with the traditional copper current leads, the reduction rate of heat leakage at the cold end of 1200 A PCLs is 30\%. That shows a huge advantage in saving energy for PCLs. The details of the iteration progress are listed in Appendix A.4.

Table 6. Three sets of optimal parameters for 1200 A PCLs.

\begin{tabular}{ccccc}
\hline \multirow{2}{*}{ Symbol } & \multirow{2}{*}{ Quantity } & \multicolumn{2}{c}{ Optimized Parameters } \\
\cline { 3 - 5 } & & Case 1 & Case 2 & Case 3 \\
\hline $\mathrm{A}: r_{1}$ & Radius of Copper leads $(\mathrm{mm})$ & 10.0 & 15.5 & 20.0 \\
$\mathrm{~B}: L_{1}$ & Length of warm end copper leads $(\mathrm{mm})$ & 10.0 & 10.0 & 10.0 \\
$\mathrm{C}: L_{3}$ & Length of cold end copper leads $(\mathrm{mm})$ & 700.0 & 1700.0 & 2900.0 \\
$\mathrm{D}: r_{2}$ & Radius of $\mathrm{Bi}_{2} \mathrm{Te}_{3}(\mathrm{~mm})$ & 15.0 & 20.0 & 30.0 \\
$\mathrm{E}: L_{2}$ & Length of $\mathrm{Bi}_{2} \mathrm{Te}_{3}(\mathrm{~mm})$ & 1.5 & 3.5 & 7.5 \\
& Lowest heat leakage $(\mathrm{W} / \mathrm{kA})$ & 29.9 & 29.6 & 29.8 \\
& Heat leakage with pure copper $(\mathrm{W} / \mathrm{kA})$ & 45.1 & 43.8 & 44.6 \\
\multicolumn{2}{r}{ Reduction rate of cold end heat leakage } & $33.7 \%$ & $32.5 \%$ & $33.2 \%$ \\
\hline
\end{tabular}

From Table 6 we find that the optimal values for $r_{2}$ in the three cases are $15.0 \mathrm{~mm}$, $20.0 \mathrm{~mm}$, and $30.0 \mathrm{~mm}$, which are a little larger than the radius of copper leads. Through the optimization process (A4), we know that though the value of $r_{2}$ (radius of $\mathrm{Bi}_{2} \mathrm{Te}_{3}$ ) has a great influence on the heat leakage of PCLs; when the value of $r_{2}$ is larger than a certain value (such as $15.0 \mathrm{~mm}, 20.0 \mathrm{~mm}$, or $30.0 \mathrm{~mm}$ ), the heat leakage curve will become stable at low values. Based on these considerations, the optimal values for $r_{2}$ are selected as $15.0 \mathrm{~mm}, 20.0 \mathrm{~mm}$, and $30.0 \mathrm{~mm}$. Moreover, the optimal value for $L_{1}$ in the three cases is $10.0 \mathrm{~mm}$. The reason is the same as for 120 A PCLs. Based on these settings, the optimal values of $1200 \mathrm{~A}$ PCLs for $L_{2}$ and $L_{3}$ are also increased with the increase in the radius of copper leads $r_{1}$. Furthermore, the problem of optimization of the 1200 A PCLs is also a 
multisolution problem, where there exists a wide variety in the optimal ratios of $(\mathrm{L} / \mathrm{A})_{\mathrm{p}}$ and $(\mathrm{L} / \mathrm{A})_{\mathrm{c}}$.

The lowest heat leakage found for $1200 \mathrm{~A}$ PCLs, nearly $30.0 \mathrm{~W} / \mathrm{kA}$, is at the same level as that found for 120 A PCLs. This indicates that the heat leakage for a multiterminal current lead connector with a total current of $1200 \mathrm{~A}$ is equal to that of a single PCL with a current of $1200 \mathrm{~A}$. When taking the heat dissipation area at the hot end into account, multiterminal solutions are better solutions for kiloampere current leads.

\section{Conclusions}

Through a COMSOL two-dimensional axisymmetric model of PCL finite element simulation, this study first used the orthogonal experiment to scientifically choose the parameters that have a great influence on the heat leakage at the cold end. Through our simulation, we firstly found that the coupling effect between the radius of $\mathrm{Bi}_{2} \mathrm{Te}_{3}\left(r_{2}\right)$ and the length of $\mathrm{Bi}_{2} \mathrm{Te}_{3}\left(L_{2}\right)$ has the greatest effect on the heat leakage of PCLs at the cold end for 120 A and 1200 A PCLs. The second and third factors for 120 A PCLs are the coupling effect between the length of warm end and cold end copper $\left(L_{1} \times L_{3}\right)$ and the radius of copper $\left(r_{1}\right)$, respectively. For 1200 A PCLs, the second and third factors are the radius of $\mathrm{Bi}_{2} \mathrm{Te}_{3}\left(r_{2}\right)$ and the length of $\mathrm{Bi}_{2} \mathrm{Te}_{3}\left(L_{2}\right)$, respectively.

Based on these more influential parameters, the optimization range was narrowed. Through parametric sweep iteration, by changing the initial values for different dimensional parameters slightly, we obtained several sets of optimal parameter sizes. We found that the problem of optimization of the 120 A and 1200 A PCLs is a multisolution problem, where there exists a wide variety in the optimal ratios of $(\mathrm{L} / \mathrm{A})_{\mathrm{p}}$ and $(\mathrm{L} / \mathrm{A})_{\mathrm{c}}$. Therefore, in the practical application design, it is more necessary to consider the important factors affecting the heat leakage at the cold end $\left(r_{2} \times L_{2}, L_{1} \times L_{3}, r_{1}\right)$.

Through our calculation comparison, we determined that the lowest cold end leakage heat for PCLs of $120 \mathrm{~A}$ and $1200 \mathrm{~A}$ is close to $30.0 \mathrm{~W} / \mathrm{kA}$. This indicates that the heat leakage for a multiterminal current lead connector with a total current of $1200 \mathrm{~A}$ is equal to that of a single PCL with a current of 1200 A. When taking the heat dissipation area on the hot end into account, multiterminal solutions are better solutions for kiloampere current leads. The method developed in this work significantly reduces the number of simulation cases and improves the comprehensiveness of optimal solutions. This method can be used to optimize HTS current leads with more complex structures and materials to reduce overall heat leakage, which deserves future work.

Author Contributions: S.Z. and S.D. contributed to the overall study design and analysis. L.L. (Linying Liu) contributed to computer simulation and writing of the manuscript. S.Z., S.D., L.L. (Lingfeng Lai), and C.G. provided technical support and revised the manuscript. S.Z. and L.L. (Linying Liu) provided funding acquisition. All authors have read and agreed to the published version of the manuscript.

Funding: This work was supported in part by the National Science Foundation of China under Grant 51807192 and in part by the China Post Doctoral Science Foundation under Grant 2020M671917.

Conflicts of Interest: The authors declare no conflict of interest.

\section{Appendix A}

Appendix A.1 Orthogonal Experimental Schedule for 120 A PCLs

Before solving the optimization problems, we usually need to choose a suitable orthogonal table. Based on the number and level of the parameter factors, we need to design the header of the orthogonal table. Then, we carry out the orthogonal experiment. More information about orthogonal experimental design can be found in [35]. Table A1 is the orthogonal experimental schedule for the 120 A PCLs, which is a very important intermediate process for the orthogonal experiment. 
Table A1. Orthogonal experimental schedule for 120 A PCLs.

\begin{tabular}{|c|c|c|c|c|c|c|}
\hline $\begin{array}{l}\text { Column } \\
\text { Number }\end{array}$ & 1 & 2 & 4 & 8 & 15 & \\
\hline Parameters & $\begin{array}{c}\text { A: Copper } \\
\text { Leads Radius } \\
\left(r_{1} / \mathrm{mm}\right)\end{array}$ & $\begin{array}{c}\text { B: Length of } \\
\text { Warm end } \\
\text { Copper Leads } \\
\left(L_{1} / \mathrm{mm}\right)\end{array}$ & $\begin{array}{c}\text { C: Length of } \\
\text { Cold End } \\
\text { Copper Leads } \\
\left(L_{3} / \mathrm{mm}\right)\end{array}$ & $\begin{array}{c}\text { D: Radius of } \\
\mathrm{Bi}_{2} \mathrm{Te}_{3}\left(r_{2} / \mathrm{mm}\right)\end{array}$ & $\begin{array}{c}\text { E: Length of } \\
\mathrm{Bi}_{2} \mathrm{Te}_{3}\left(L_{2} / \mathrm{mm}\right)\end{array}$ & $\begin{array}{c}\text { Simulation } \\
\text { Results (W/kA) }\end{array}$ \\
\hline Simulation 1 & 3.0 & 10.0 & 100.0 & 1.0 & 1.0 & 154.9 \\
\hline Simulation 2 & 3.0 & 10.0 & 100.0 & 30.0 & 30.0 & 76.1 \\
\hline Simulation 3 & 3.0 & 10.0 & 1500.0 & 1.0 & 30.0 & 1608.3 \\
\hline Simulation 4 & 3.0 & 10.0 & 1500.0 & 30.0 & 1.0 & 158.8 \\
\hline Simulation 5 & 3.0 & 300.0 & 100.0 & 1.0 & 30.0 & 4920.0 \\
\hline Simulation 6 & 3.0 & 300.0 & 100.0 & 30.0 & 1.0 & 74.1 \\
\hline Simulation 7 & 3.0 & 300.0 & 1500.0 & 1.0 & 1.0 & 384.7 \\
\hline Simulation 8 & 3.0 & 300.0 & 1500.0 & 30.0 & 30.0 & 351.9 \\
\hline Simulation 9 & 30.0 & 10.0 & 100.0 & 1.0 & 30.0 & 5676.9 \\
\hline Simulation 10 & 30.0 & 10.0 & 100.0 & 30.0 & 1.0 & 5816.0 \\
\hline Simulation 11 & 30.0 & 10.0 & 1500.0 & 1.0 & 1.0 & 178.6 \\
\hline Simulation 12 & 30.0 & 10.0 & 1500.0 & 30.0 & 30.0 & 215.8 \\
\hline Simulation 13 & 30.0 & 300.0 & 100.0 & 1.0 & 1.0 & 183.9 \\
\hline Simulation 14 & 30.0 & 300.0 & 100.0 & 30.0 & 30.0 & 244.6 \\
\hline Simulation 15 & 30.0 & 300.0 & 1500.0 & 1.0 & 30.0 & 5507.5 \\
\hline Simulation 16 & 30.0 & 300.0 & 1500.0 & 30.0 & 1.0 & 1066.6 \\
\hline
\end{tabular}

Appendix A.2 Global Optimization of the PCLs for 120 A PCLs

Appendix A.2.1 The Simulation Case 2 for 120 A PCLs

Based on the orthogonal experimental results in Section 3.1.2, we know the first set of parameters that have the greatest effect on the heat leakage at the cold end is $\mathrm{D} \times \mathrm{E}, \mathrm{B} \times \mathrm{C}$, and $\mathrm{A}$. Thus, we first optimize the parameter of the interaction between $\mathrm{D}$ (radius of $\mathrm{Bi}_{2} \mathrm{Te}_{3}$, $r_{2}$ ) and $\mathrm{E}$ (length of $\mathrm{Bi}_{2} \mathrm{Te}_{3}, L_{2}$ ) to reveal their coupling influence on the heat leakage at the cold end (as shown in Figure A1), keeping the other parameters unchanged (radius of copper leads $r_{1}=3.0 \mathrm{~mm}$, length of warm end copper leads $L_{3}=10.0 \mathrm{~mm}$, length of cold end copper leads $L_{1}=1000.0 \mathrm{~mm}$ ).

Then, we change the initial values for different dimensional parameters slightly, and through parametric sweep iteration, we obtain another two sets of optimal parameter sizes corresponding to a minimum heat leakage of PCLs, as shown in Figures A1-A3 and Figures A4-A6, respectively.
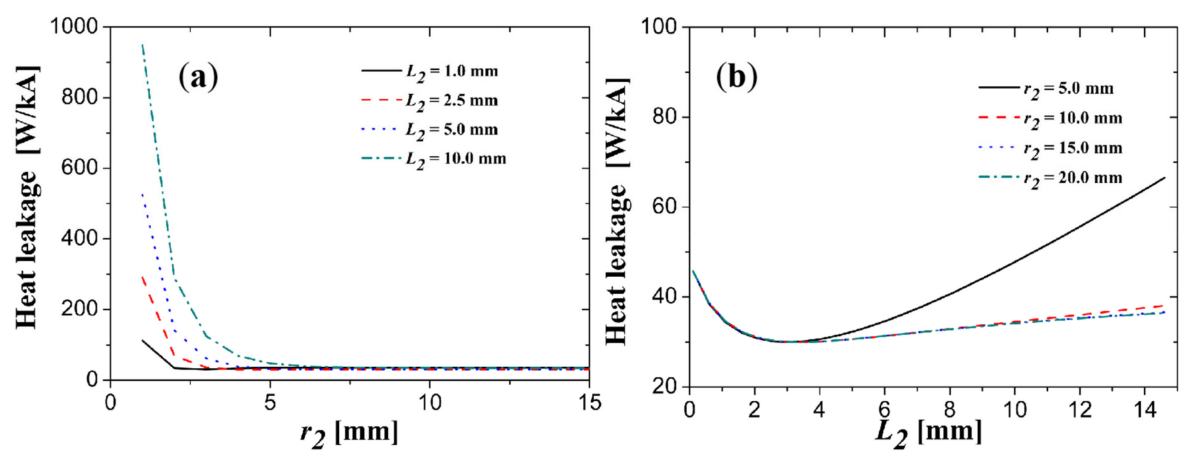

Figure A1. Iteration step 1: the coupling influence between $\mathrm{D}\left(r_{2}\right)$ and $\mathrm{E}\left(L_{2}\right)$ on the cold end heat leakage of PCLs (keeping parameters $r_{1}=4.0 \mathrm{~mm}, L_{1}=10.0 \mathrm{~mm}, L_{3}=1500.0 \mathrm{~mm}$ unchanged; in this iteration $\left.\mathrm{Q}_{\min }=30.0 \mathrm{~W} / \mathrm{kA}\right)$. (a) The heat leakage vary with $\mathrm{D}\left(r_{2}\right)$; (b)The heat leakage vary with $\mathrm{E}\left(L_{2}\right)$. 

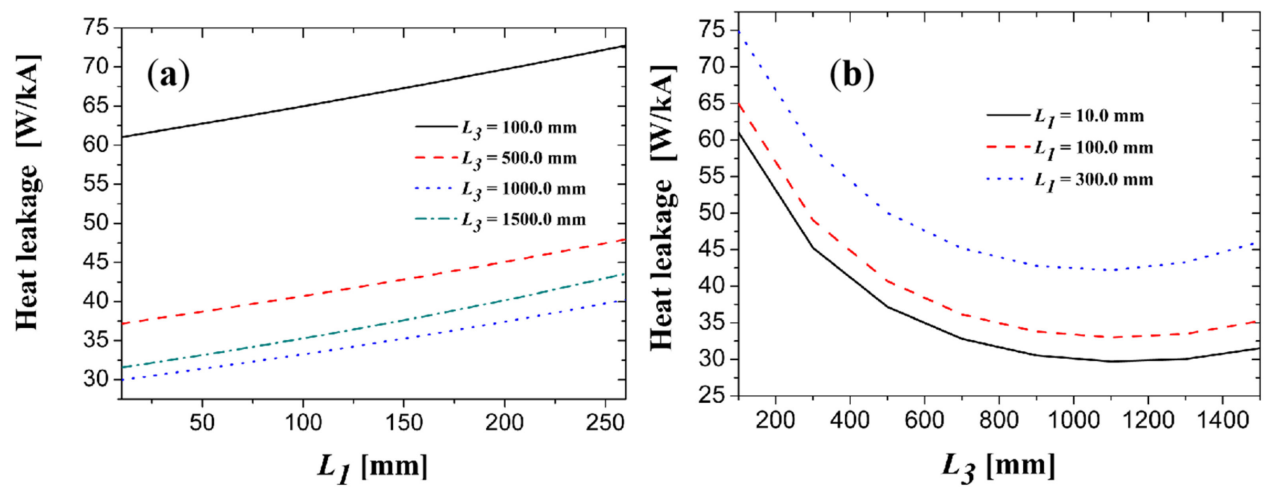

Figure A2. Iteration step 2: the coupling influence between $\mathbf{B}\left(L_{1}\right)$ and $\mathbf{C}\left(L_{3}\right)$ on the cold end heat leakage of PCLs (keeping parameters $r_{1}=4.0 \mathrm{~mm}, r_{2}=10.0 \mathrm{~mm}, L_{2}=3.5 \mathrm{~mm}$ unchanged; in this iteration $\left.Q_{\min }=29.7 \mathrm{~W} / \mathrm{kA}\right)$. (a) The heat leakage vary with $\mathrm{B}\left(L_{1}\right)$; (b)The heat leakage vary with $\mathrm{C}\left(L_{3}\right)$.

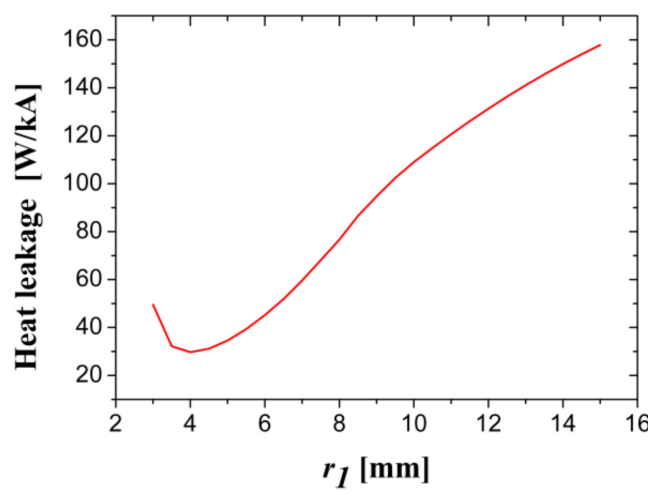

Figure A3. Iteration step 3: the effect of radius of the copper leads $r_{1}$ on the cold end heat leakage of PCLs (keeping parameters $L_{1}=10.0 \mathrm{~mm}, L_{3}=1100.0 \mathrm{~mm}, r_{2}=10.0 \mathrm{~mm}, L_{2}=3.5 \mathrm{~mm}$ unchanged; in this iteration $Q_{\min }=29.7 \mathrm{~W} / \mathrm{kA}$ ).

Appendix A.2.2 The Simulation Case 3 for 120 A PCLs
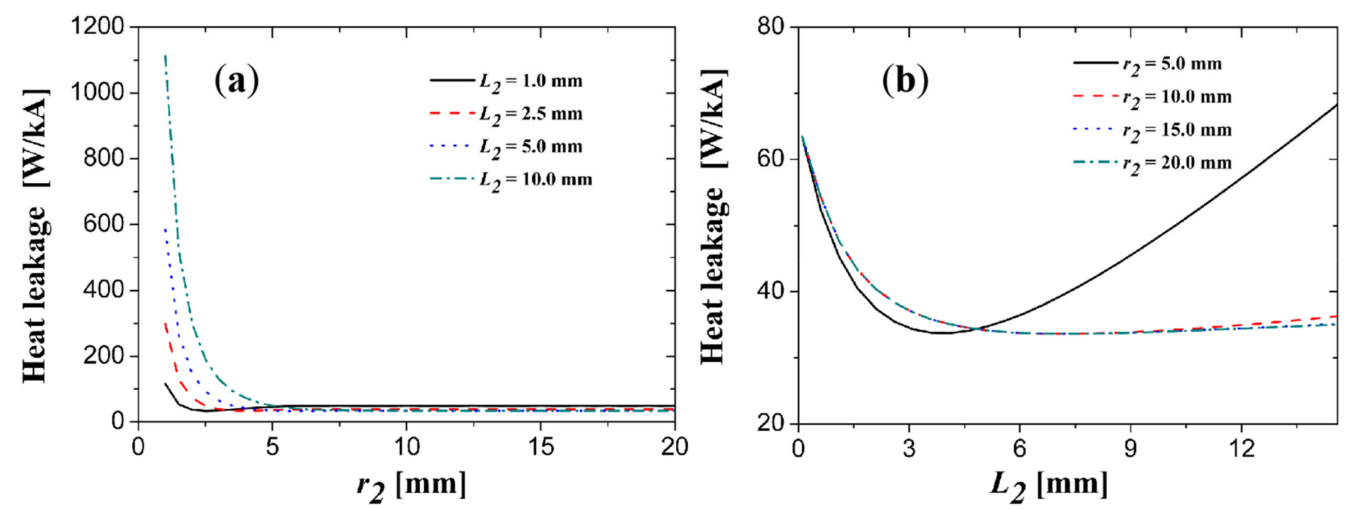

Figure A4. Iteration step 1: the coupling influence between $\mathrm{D}\left(r_{2}\right)$ and $\mathrm{E}\left(L_{2}\right)$ on the cold end heat leakage of PCLs (keeping parameters $r_{1}=5.0 \mathrm{~mm}, L_{1}=10.0 \mathrm{~mm}, L_{3}=1500.0 \mathrm{~mm}$ unchanged; in this iteration $\left.Q_{\min }=33.6 \mathrm{~W} / \mathrm{kA}\right)$. (a) The heat leakage vary with $\mathrm{D}\left(r_{2}\right)$; (b)The heat leakage vary with $\mathrm{E}\left(L_{2}\right)$. 

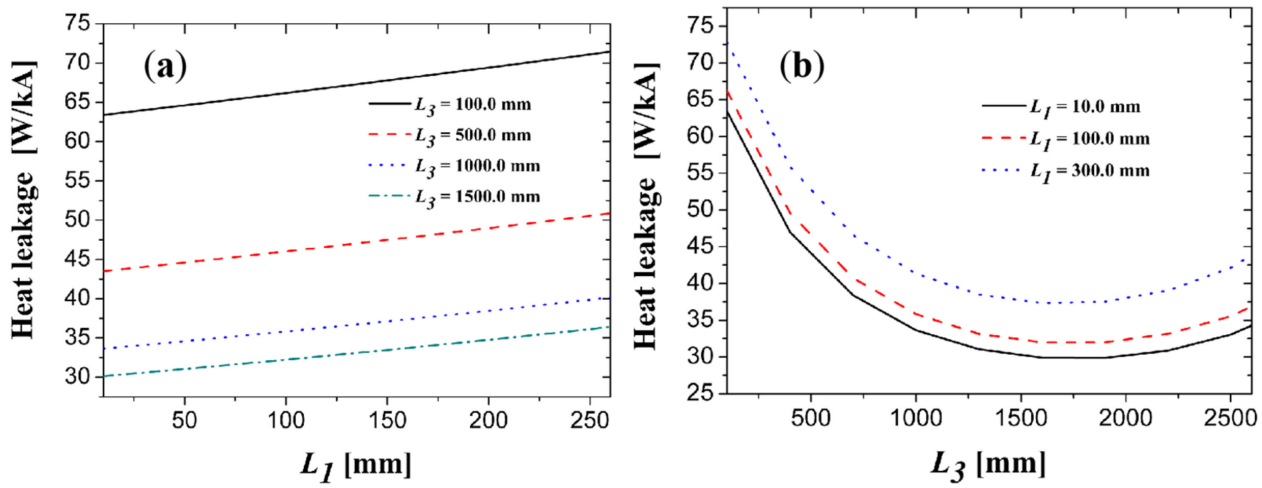

Figure A5. Iteration step 2: the coupling influence between $\mathrm{B}\left(L_{1}\right)$ and $\mathrm{C}\left(L_{3}\right)$ on the cold end heat leakage of PCLs (keeping parameters $r_{1}=5.0 \mathrm{~mm}, r_{2}=10.0 \mathrm{~mm}, L_{2}=7.0 \mathrm{~mm}$ unchanged, in this iteration $\left.Q_{\min }=29.9 \mathrm{~W} / \mathrm{kA}\right)$. (a) The heat leakage vary with $\mathrm{B}\left(L_{1}\right)$; (b)The heat leakage vary with $\mathrm{C}\left(L_{3}\right)$.

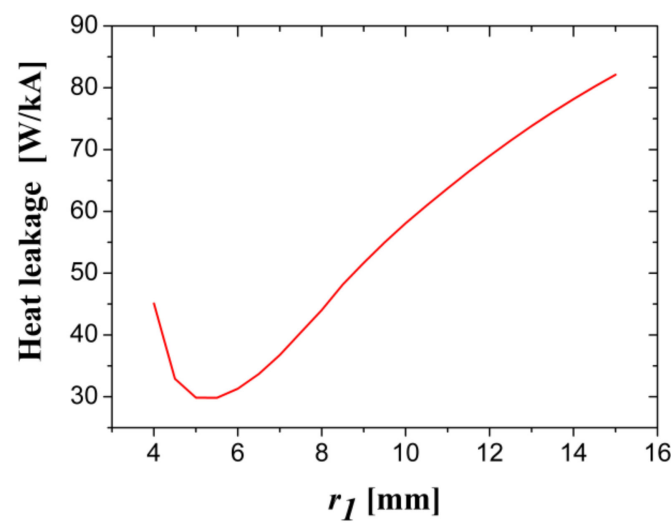

Figure A6. Iteration step three: the effect of radius of the copper leads $r_{1}$ on the cold end heat leakage of PCLs (keeping parameters $L_{1}=10.0 \mathrm{~mm}, L_{3}=1900.0 \mathrm{~mm}, r_{2}=10.0 \mathrm{~mm}, L_{2}=7.0 \mathrm{~mm}$ unchanged; in this iteration $Q_{\min }=29.8 \mathrm{~W} / \mathrm{kA}$ ).

Appendix A.3 Orthogonal Experimental Schedule for 1200 A PCLs

Table A2 is the orthogonal experimental schedule for the 1200 A PCLs, which is a very important intermediate process for the orthogonal experiment.

Appendix A.4 Global Optimization of the PCLs for 1200 A PCLs Appendix A.4.1 The Simulation Case 1 for 1200 A PCLs

Based on the orthogonal experimental results in Section 3.2.2, we know the first set of parameters that have the greatest effect on the heat leakage at the cold end is $\mathrm{D} \times \mathrm{E}, \mathrm{D}, \mathrm{E}$, $\mathrm{B} \times \mathrm{C}$, and $\mathrm{A}$. To some extent, this is consistent with the order of orthogonal experimental results for the 120 A PCLs: $\mathrm{D} \times \mathrm{E}, \mathrm{B} \times \mathrm{C}$, and A. Thus, we first optimize the parameter of the interaction between $\mathrm{D}$ (radius of $\mathrm{Bi}_{2} \mathrm{Te}_{3}, r_{2}$ ) and $\mathrm{E}$ (length of $\mathrm{Bi}_{2} \mathrm{Te}_{3}, L_{2}$ ) to reveal their coupling influence on the heat leakage at the cold end (as shown in Figure A7), keeping the other parameters unchanged (radius of copper leads $r_{1}=10.0 \mathrm{~mm}$, length of warm end copper leads $L_{1}=100.0 \mathrm{~mm}$, length of cold end copper leads $L_{3}=500.0 \mathrm{~mm}$ ). 
Table A2. Orthogonal experimental schedule for 1200 A PCLs.

\begin{tabular}{|c|c|c|c|c|c|c|}
\hline $\begin{array}{l}\text { Column } \\
\text { Number }\end{array}$ & 1 & 2 & 4 & 8 & 15 & \\
\hline Parameters & $\begin{array}{l}\text { A: Copper } \\
\text { Leads Radius } \\
\left(r_{1} / \mathrm{mm}\right)\end{array}$ & $\begin{array}{c}\text { B: Length of } \\
\text { Warm End } \\
\text { Copper Leads } \\
\left(L_{1} / \mathrm{mm}\right)\end{array}$ & $\begin{array}{c}\text { C: Length of } \\
\text { Cold End } \\
\text { Copper Leads } \\
\left(L_{3} / \mathrm{mm}\right)\end{array}$ & $\begin{array}{c}\text { D: Radius of } \\
\mathrm{Bi}_{2} \mathrm{Te}_{3}\left(r_{2} / \mathrm{mm}\right)\end{array}$ & $\begin{array}{c}\text { E: Length of } \\
\mathrm{Bi}_{2} \mathrm{Te}_{3}\left(L_{2} / \mathrm{mm}\right)\end{array}$ & $\begin{array}{c}\text { Simulation } \\
\text { Results (W/kA) }\end{array}$ \\
\hline Simulation 1 & 10.0 & 10.0 & 100.0 & 5.0 & 1.0 & 69.7 \\
\hline Simulation 2 & 10.0 & 10.0 & 100.0 & 50.0 & 50.0 & 196.5 \\
\hline Simulation 3 & 10.0 & 10.0 & 1500.0 & 5.0 & 50.0 & 1254.7 \\
\hline Simulation 4 & 10.0 & 10.0 & 1500.0 & 50.0 & 1.0 & 68.6 \\
\hline Simulation 5 & 10.0 & 300.0 & 100.0 & 5.0 & 50.0 & 3482.7 \\
\hline Simulation 6 & 10.0 & 300.0 & 100.0 & 50.0 & 1.0 & 74.0 \\
\hline Simulation 7 & 10.0 & 300.0 & 1500.0 & 5.0 & 1.0 & 304.4 \\
\hline Simulation 8 & 10.0 & 300.0 & 1500.0 & 50.0 & 50.0 & 357.8 \\
\hline Simulation 9 & 80.0 & 10.0 & 100.0 & 5.0 & 50.0 & 3774.3 \\
\hline Simulation 10 & 80.0 & 10.0 & 100.0 & 50.0 & 1.0 & 1845.0 \\
\hline Simulation 11 & 80.0 & 10.0 & 1500.0 & 5.0 & 1.0 & 78.6 \\
\hline Simulation 12 & 80.0 & 10.0 & 1500.0 & 50.0 & 50.0 & 63.2 \\
\hline Simulation 13 & 80.0 & 300.0 & 100.0 & 5.0 & 1.0 & 83.0 \\
\hline Simulation 14 & 80.0 & 300.0 & 100.0 & 50.0 & 50.0 & 67.5 \\
\hline Simulation 15 & 80.0 & 300.0 & 1500.0 & 5.0 & 50.0 & 3617.8 \\
\hline Simulation 16 & 80.0 & 300.0 & 1500.0 & 50.0 & 1.0 & 612.8 \\
\hline
\end{tabular}
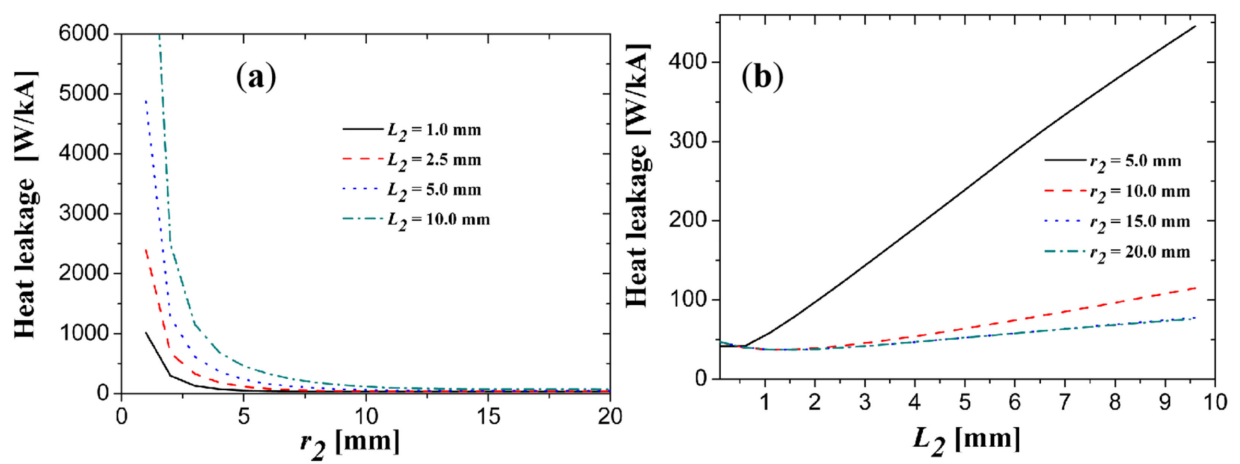

Figure A7. The coupling influence between D $\left(r_{2}\right)$ and $\mathrm{E}\left(L_{2}\right)$ on the cold end heat leakage of PCLs. (a) The heat leakage vary with $\mathrm{D}\left(r_{2}\right)$; (b)The heat leakage vary with $\mathrm{E}\left(L_{2}\right)$.

It can be seen in Figure A7a that the use of a smaller $L_{2}$ leads to achieving a smaller heat leakage value (black curve). From Figure A7b, we find that if $r_{2} \geq 15.0 \mathrm{~mm}$, the heat leakage curves are similar. Hence, we set the value of parameters D and $\mathrm{E}\left(r_{2}=15.0 \mathrm{~mm}, L_{2}\right.$ $=1.6 \mathrm{~mm}$ ) and fix them in the next iteration. For the first iteration, the lowest heat leakage at the cold end of PCLs is $37.2 \mathrm{~W} / \mathrm{kA}$.

Then, we optimize the parameter of the interaction between $\mathrm{B}\left(L_{1}\right)$ and $\mathrm{C}\left(L_{3}\right)$ to reveal their coupling influence on the heat leakage at the cold end (as shown in Figure A8), keeping the other parameters unchanged $\left(r_{1}=10.0 \mathrm{~mm}, r_{2}=15.0 \mathrm{~mm}, L_{2}=1.6 \mathrm{~mm}\right)$. As shown in Figure A8a, the optimal value of cold end copper leads $\left(L_{3}\right)$ is some intermediate value, which is confirmed by Figure A8b. With the increase in the length of cold end copper leads $\left(L_{3}\right)$, the heat leakage curve is decreased first and then increased (Figure A8b). Hence, we obtain the best values for B and C $\left(L_{1}=10.0 \mathrm{~mm}, L_{3}=700.0 \mathrm{~mm}\right)$. Under these optimization parameters, the lowest heat leakage at the cold end of PCLs is $29.9 \mathrm{~W} / \mathrm{kA}$. 

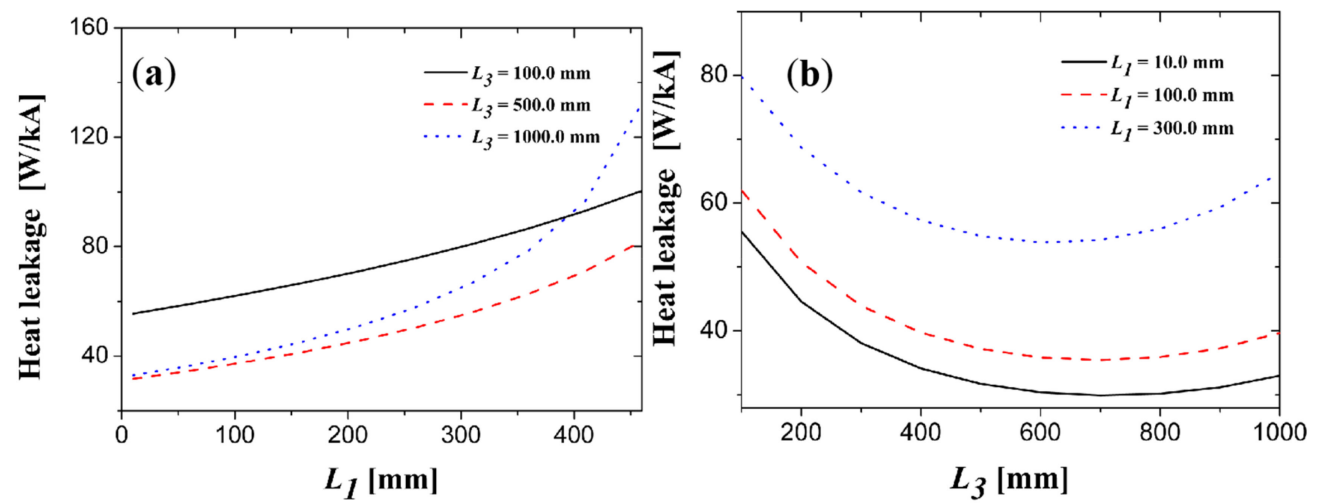

Figure A8. The coupling influence between B $\left(L_{1}\right)$ and $C\left(L_{3}\right)$ on the cold end heat leakage of PCLs. (a) The heat leakage vary with $\mathrm{B}\left(L_{1}\right)$; (b)The heat leakage vary with $\mathrm{C}\left(L_{3}\right)$.

Finally, we optimize the parameter A (radius of the copper leads $r_{1}$ ), keeping the other parameters unchanged $\left(L_{1}=10.0 \mathrm{~mm}, L_{3}=700.0 \mathrm{~mm}, r_{2}=15.0 \mathrm{~mm}, L_{2}=1.6 \mathrm{~mm}\right)$. Figure A9 illustrates the effect of $r_{1}$ on the heat leakage of PCLs. Here, we obtain the best value for $r_{1}=10.0 \mathrm{~mm}$ and achieve an optimized structure of PCLs with the lowest heat leakage of $29.9 \mathrm{~W} / \mathrm{kA}$.

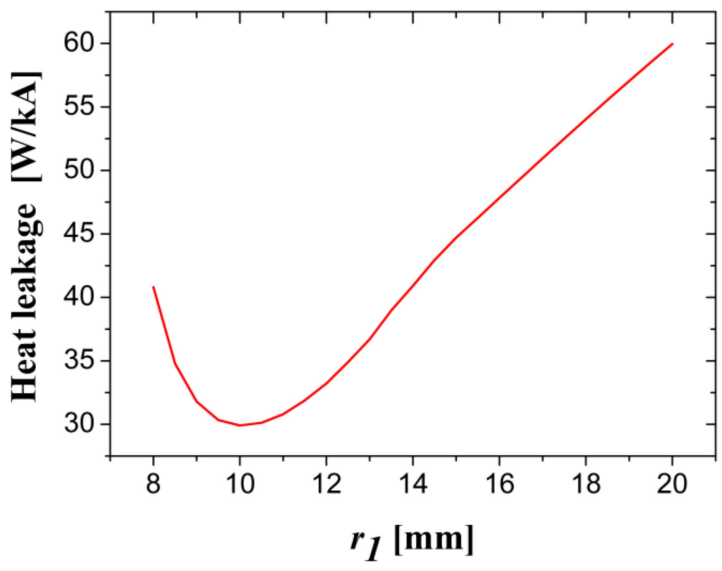

Figure A9. The effect of radius of the copper leads $r_{1}$ on the cold end heat leakage of PCLs.

Then, we change the initial values for different dimensional parameters slightly, and through parametric sweep iteration, we obtain another two sets of optimal parameter sizes corresponding to a minimum heat leakage of PCLs, as shown in Figures A10-A12 and Figures A13-A15, respectively.

Appendix A.4.2 The Simulation Case 2 for 1200 A PCLs

Based on the orthogonal experimental results presented in Section 3.2.2, we know the set of parameters that have the greatest effect on the heat leakage at the cold end is $\mathrm{D} \times \mathrm{E}, \mathrm{D}$, $\mathrm{E}, \mathrm{B} \times \mathrm{C}$, and $\mathrm{A}$. Thus, we first optimize the parameter of the interaction between $\mathrm{D}$ (radius of $\mathrm{Bi}_{2} \mathrm{Te}_{3}, r_{2}$ ) and $\mathrm{E}$ (length of $\mathrm{Bi}_{2} \mathrm{Te}_{3}, L_{2}$ ) to reveal their coupling influence on the heat leakage at the cold end (as shown in Figure A10), keeping the other parameters unchanged (radius of copper leads $r_{1}=15.0 \mathrm{~mm}$, length of warm end copper leads $L_{1}=100.0 \mathrm{~mm}$, length of cold end copper leads $L_{3}=1500.0 \mathrm{~mm}$ ). 

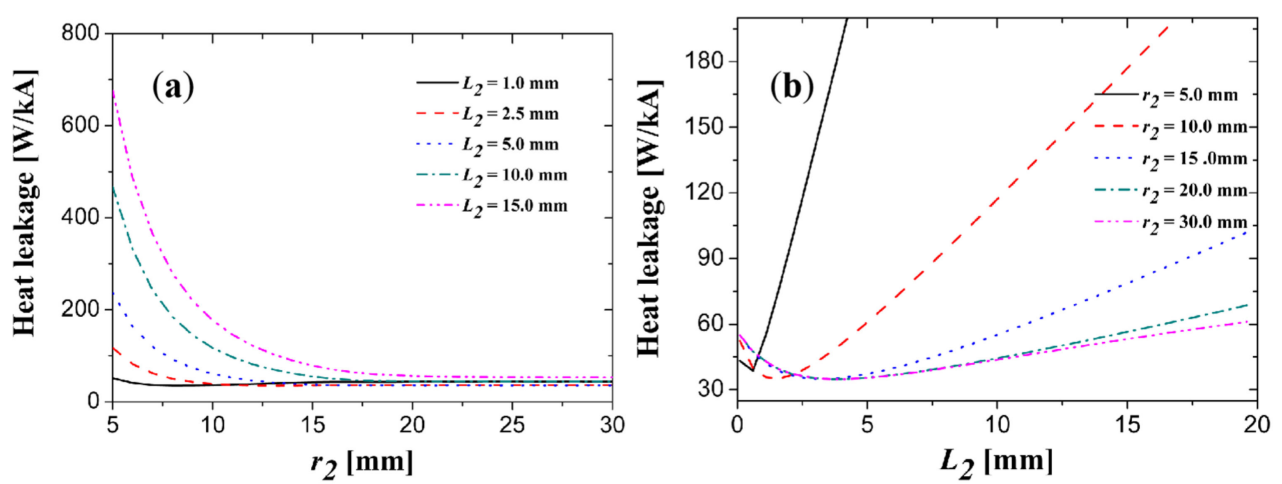

Figure A10. Iteration step one: the coupling influence between $\mathrm{D}\left(r_{2}\right)$ and $\mathrm{E}\left(L_{2}\right)$ on the cold end heat leakage of PCLs (keeping parameters $r_{1}=15.0 \mathrm{~mm}, L_{1}=100.0 \mathrm{~mm}, L_{3}=1500.0 \mathrm{~mm}$ unchanged; in this iteration $\mathrm{Q}_{\min }=34.9 \mathrm{~W} / \mathrm{kA}$ ). (a) The heat leakage vary with $\mathrm{D}\left(r_{2}\right)$; (b)The heat leakage vary with $\mathrm{E}\left(L_{2}\right)$.

Then, we optimize the parameter of the interaction between $\mathrm{B}\left(L_{1}\right)$ and $\mathrm{C}\left(L_{3}\right)$ to reveal their coupling influence on the heat leakage at the cold end (as shown in Figure A11), keeping the other parameters unchanged $\left(r_{1}=15.0 \mathrm{~mm}, r_{2}=20.0 \mathrm{~mm}, L_{2}=3.5 \mathrm{~mm}\right)$. As shown in Figure A11, we obtain the best values for B and $C\left(L_{1}=10.0 \mathrm{~mm}, L_{3}=1700.0 \mathrm{~mm}\right)$. Under these optimization parameters, the lowest heat leakage at the cold end of PCLs is $29.6 \mathrm{~W} / \mathrm{kA}$.

Finally, we optimize the parameter A (radius of the copper leads $r_{1}$ ), keeping the other parameters unchanged $\left(L_{1}=10.0 \mathrm{~mm}, L_{3}=1700.0 \mathrm{~mm}, r_{2}=20.0 \mathrm{~mm}, L_{2}=3.5 \mathrm{~mm}\right)$. Figure A12 illustrates the effect of $r_{1}$ on the heat leakage of PCLs. Here, we obtain the best value for $r_{1}=15.5 \mathrm{~mm}$ and achieve an optimized structure of PCLs with the lowest heat leakage of $29.6 \mathrm{~W} / \mathrm{kA}$.
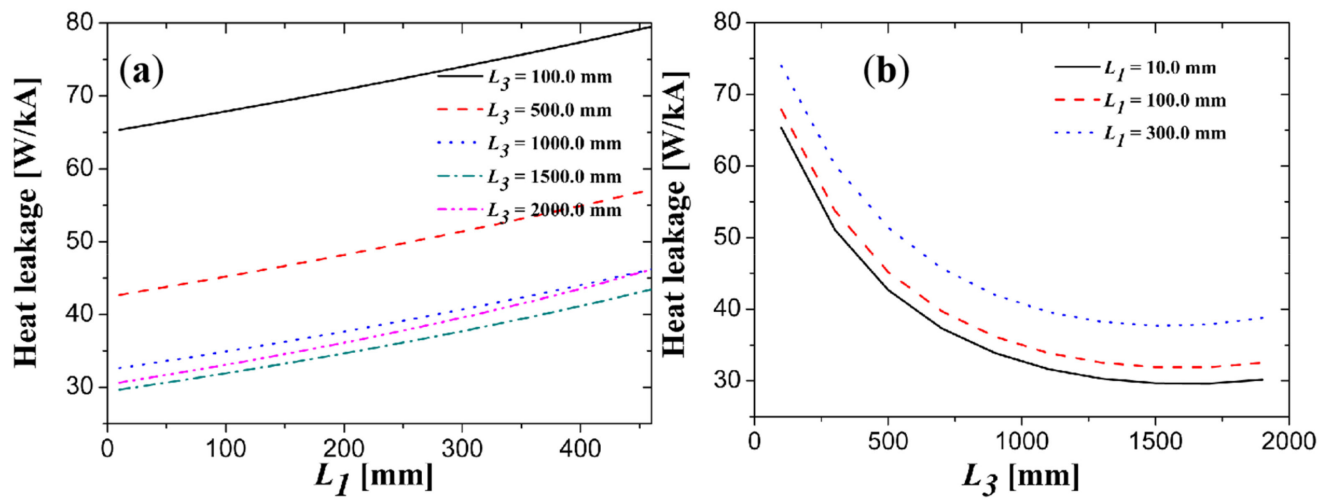

Figure A11. Iteration step two: the coupling influence between $B\left(L_{1}\right)$ and $C\left(L_{3}\right)$ on the cold end heat leakage of PCLs (keeping parameters $r_{1}=15.0 \mathrm{~mm}, r_{2}=20.0 \mathrm{~mm}, L_{2}=3.5 \mathrm{~mm}$ unchanged; in this iteration $\left.\mathrm{Q}_{\min }=29.6 \mathrm{~W} / \mathrm{kA}\right)$. (a) The heat leakage vary with $\mathrm{B}\left(L_{1}\right)$; (b)The heat leakage vary with $\mathrm{C}\left(L_{3}\right)$.

\section{Appendix A.4.3 The Simulation Case 3 for 1200 A PCLs}

Based on the orthogonal experimental results presented in Section 3.2.2, we know the set of parameters that have the greatest effect on the heat leakage at the cold end is $D \times E, D$, $\mathrm{E}, \mathrm{B} \times \mathrm{C}$, and $\mathrm{A}$. Thus, we first optimize the parameter of the interaction between $\mathrm{D}$ (radius of $\mathrm{Bi}_{2} \mathrm{Te}_{3}, r_{2}$ ) and $\mathrm{E}$ (length of $\mathrm{Bi}_{2} \mathrm{Te}_{3}, L_{2}$ ) to reveal their coupling influence on the heat leakage at the cold end (as shown in Figure A13), keeping the other parameters unchanged (radius of copper leads $r_{1}=20.0 \mathrm{~mm}$, length of warm end copper leads $L_{1}=100.0 \mathrm{~mm}$, length of cold end copper leads $L_{3}=1500.0 \mathrm{~mm}$ ). 


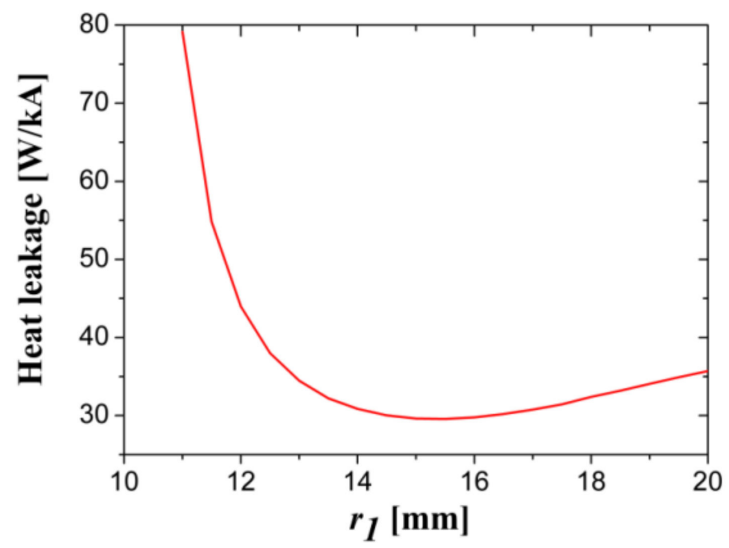

Figure A12. Iteration step three: the effect of radius of the copper leads $r_{1}$ on the cold end heat leakage of PCLs (keeping parameters $L_{1}=10.0 \mathrm{~mm}, L_{3}=1700.0 \mathrm{~mm}, r_{2}=20.0 \mathrm{~mm}, L_{2}=3.5 \mathrm{~mm}$ unchanged; in this iteration $\mathrm{Q}_{\min }=29.6 \mathrm{~W} / \mathrm{kA}$ ).
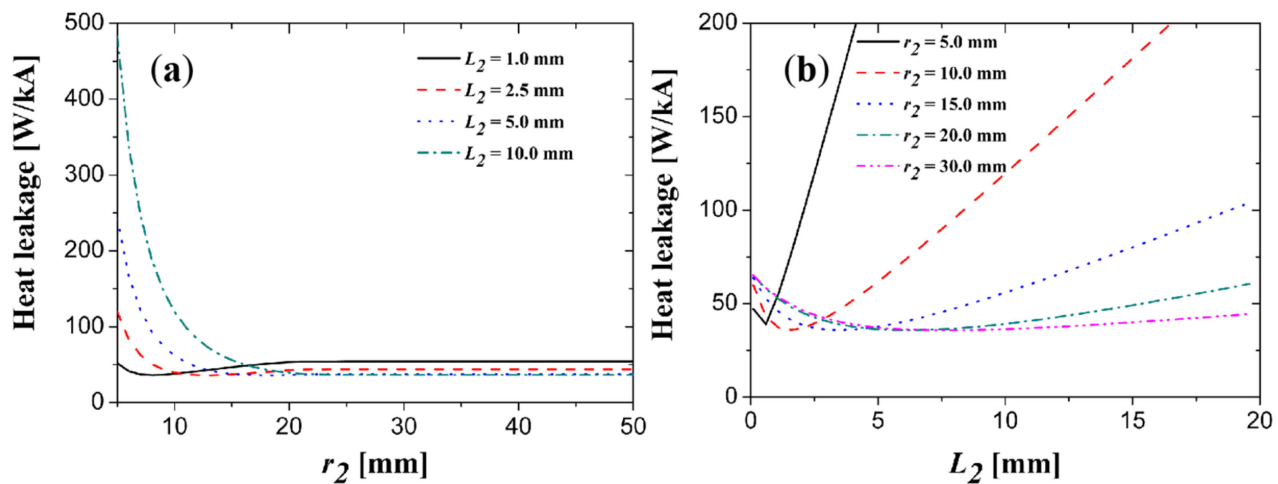

Figure A13. Iteration step one: the coupling influence between $\mathrm{D}\left(r_{2}\right)$ and $\mathrm{E}\left(L_{2}\right)$ on the cold end heat leakage of PCLs (keeping parameters $r_{1}=20.0 \mathrm{~mm}, L_{1}=100.0 \mathrm{~mm}, L_{3}=1500.0 \mathrm{~mm}$ unchanged; in this iteration $Q_{\min }=35.7 \mathrm{~W} / \mathrm{kA}$ ). (a) The heat leakage vary with $\mathrm{D}\left(r_{2}\right)$; (b)The heat leakage vary with $\mathrm{E}\left(L_{2}\right)$.

Then, we optimize the parameter of the interaction between $B\left(L_{1}\right)$ and $C\left(L_{3}\right)$ to reveal their coupling influence on the heat leakage at the cold end (as shown in Figure A14), keeping the other parameters unchanged $\left(r_{1}=20.0 \mathrm{~mm}, r_{2}=30.0 \mathrm{~mm}, L_{2}=7.5 \mathrm{~mm}\right)$. As shown in Figure A14, we obtain the best values for B and C $\left(L_{1}=10.0 \mathrm{~mm}, L_{3}=2900.0 \mathrm{~mm}\right)$. Under these optimization parameters, the lowest heat leakage at the cold end of PCLs is $29.9 \mathrm{~W} / \mathrm{kA}$.

Finally, we optimize the parameter A (radius of the copper leads $r_{1}$ ), keeping the other parameters unchanged $\left(L_{1}=10.0 \mathrm{~mm}, L_{3}=2900.0 \mathrm{~mm}, r_{2}=30.0 \mathrm{~mm}, L_{2}=7.5 \mathrm{~mm}\right)$. Figure A15 illustrates the effect of $r_{1}$ on the heat leakage of PCLs. Here, we obtain the best value for $r_{1}=20.0 \mathrm{~mm}$ and achieve an optimized structure of PCLs with the lowest heat leakage of $29.8 \mathrm{~W} / \mathrm{kA}$. 

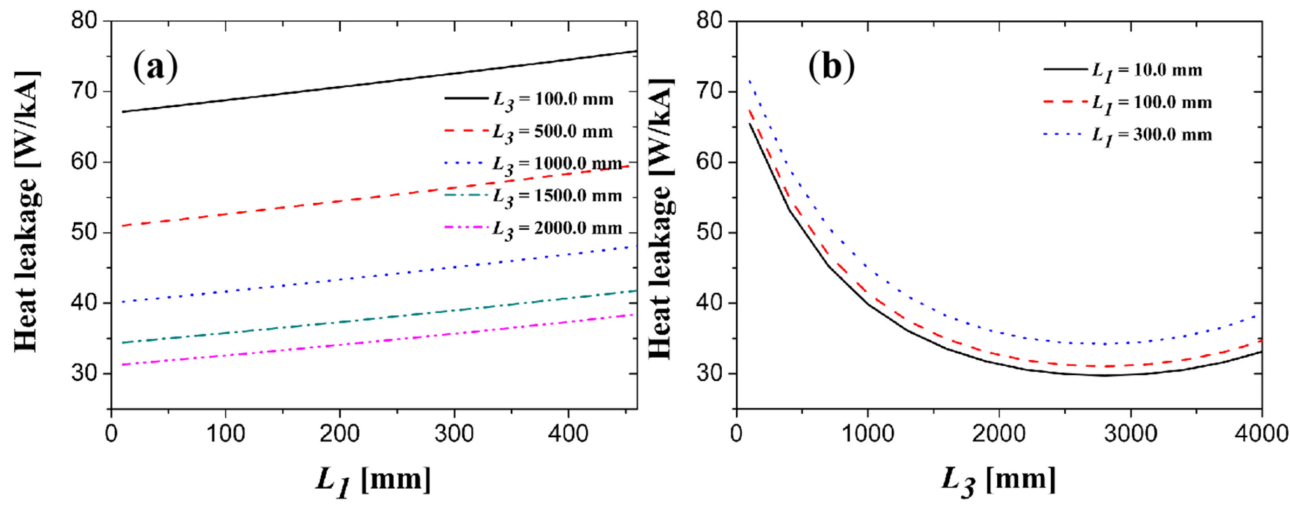

Figure A14. Iteration step two: the coupling influence between $B\left(L_{1}\right)$ and $C\left(L_{3}\right)$ on the cold end heat leakage of PCLs (keeping parameters $r_{1}=20.0 \mathrm{~mm}, r_{2}=30.0 \mathrm{~mm}, L_{2}=7.5 \mathrm{~mm}$ unchanged; in this iteration $\left.Q_{\min }=29.8 \mathrm{~W} / \mathrm{kA}\right)$. (a) The heat leakage vary with $\mathrm{B}\left(L_{1}\right)$; (b)The heat leakage vary with $\mathrm{C}\left(L_{3}\right)$.

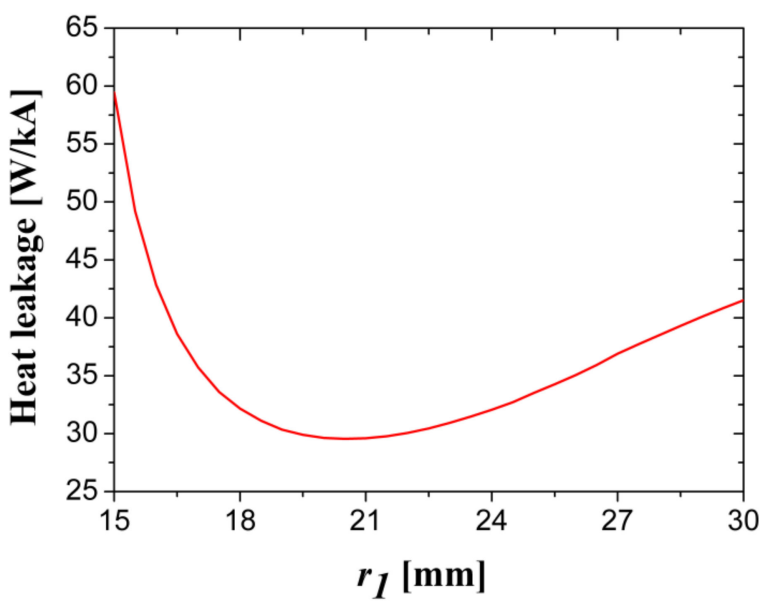

Figure A15. Iteration step three: the effect of radius of the copper leads $r_{1}$ on the cold end heat leakage of PCLs (keeping parameters $L_{1}=10.0 \mathrm{~mm}, L_{3}=2900.0 \mathrm{~mm}, r_{2}=30.0 \mathrm{~mm}, L_{2}=7.5 \mathrm{~mm}$ unchanged; in this iteration $\left.\mathrm{Q}_{\min }=29.8 \mathrm{~W} / \mathrm{kA}\right)$.

\section{References}

1. Dai, S.; Xiao, L.; Zhang, H.; Teng, Y.; Liang, X.; Song, N.; Cao, Z.; Zhu, Z.; Gao, Z.; Ma, T.; et al. Testing and Demonstration of a 10-kA HTS DC Power Cable. IEEE Trans. Appl. Supercond. 2014, 24, 99-102.

2. Yamaguchi, S.; Koshizuka, H.; Hayashi, K.; Sawamura, T. Concept and Design of 500 Meter and 1000 Meter DC Superconducting Power Cables in Ishikari. IEEE Trans. Appl. Supercond. 2015, 25, 5402504. [CrossRef]

3. Yang, B.; Kang, J.; Lee, S.; Choi, C.; Moon, Y. Qualification Test of a 80 kV 500 MW HTS DC Cable for Applying Into Real Grid. IEEE Trans. Appl. Supercond. 2015, 25, 5402705. [CrossRef]

4. Sytnikov, V.E.; Bemert, S.E.; Krivetsky, I.V.; Karpov, V.N.; Romashov, M.A.; Shakarian, Y.G.; Nosov, A.A.; Fetisov, S.S. The Test Results of AC and DC HTS Cables in Russia. IEEE Trans. Appl. Supercond. 2016, 26, 5401304. [CrossRef]

5. Xie, W.; Wei, B.G.; Yao, Z.F. Introduction of 35 kV km Level Domestic Second Generation High Temperature Superconducting Power Cable Project in Shanghai, China. J. Supercond. Nov. Magn. 2020, 33, 1927-1931. [CrossRef]

6. Lee, C.; Son, H.; Won, Y.; Kim, Y.; Ryu, C.; Park, M.; Iwakuma, M. Progress of the First Commercial Project of High-Temperature Superconducting Cables by KEPCO in Korea. Supercond. Sci. Technol. 2020, 33, 44006. [CrossRef]

7. Doukas, D.I. Superconducting Transmission Systems: Review, Classification, and Technology Readiness Assessment. IEEE Trans. Appl. Supercond. 2019, 29, 5401205. [CrossRef]

8. Chen, W.; Song, P.; Jiang, H.; Zhu, J.H.; Zou, S.N.; Qu, T.M. Investigations on Quench Recovery Characteristics of HighTemperature Superconducting Coated Conductors for Superconducting Fault Current Limiters. Electronics 2021, 10, 259. [CrossRef]

9. Hong, Z.; Sheng, J.; Yao, L.; Gu, J.; Jin, Z. The Structure, Performance and Recovery Time of a $10 \mathrm{kV}$ Resistive Type Superconducting Fault Current Limiter. IEEE Trans. Appl. Supercond. 2013, 23, 5601304. 
10. Qiu, Q.Q.; Xiao, L.Y.; Zhang, J.Y.; Zhang, Z.F.; Song, N.H.; Jing, L.W.; Zha, W.H.; Du, X.J.; Teng, Y.P.; Zhou, Z.H.; et al. Design and Test of 40-kV/2-kA DC Superconducting Fault Current Limiter. IEEE Trans. Appl. Supercond. 2020, 30, 2988068. [CrossRef]

11. Dai, S.T.; Ma, T.; Xue, C.; Zhao, L.Q.; Huang, Y.; Hu, L.; Wang, B.Z.; Zhang, T.; Xu, X.F.; Cai, L.L.; et al. Development and Test of a 220 kV/1.5 kA Resistive Type Superconducting Fault Current Limiter. Phys. C 2019, 565, 1253501. [CrossRef]

12. Hao, L.N.; Huang, Z.; Dong, F.L.; Qiu, D.R.; Shen, B.Y.; Jin, Z.J. Study on Electrodynamic Suspension System with HighTemperature Superconducting Magnets for a High-Speed Maglev Train. IEEE Trans. Appl. Supercond. 2019, $29,3600105$. [CrossRef]

13. Lee, H.W.; Kim, K.C.; Lee, J. Review of maglev train technologies. IEEE Trans. Magn. 2006, 42, 1917-1925.

14. Deng, Z.G.; Zhang, W.H.; Zheng, J.; Wang, B.; Ren, Y.; Zheng, X.X.; Zhang, J.H. A High-Temperature Superconducting MaglevEvacuated Tube Transport (HTS Maglev-ETT) Test System. IEEE Trans. Appl. Supercond. 2017, 27, 3602008. [CrossRef]

15. Deng, Z.G.; Zhang, W.H.; Zheng, J.; Ren, Y.; Jiang, D.H.; Zheng, X.X.; Zhang, J.H.; Gao, P.F.; Lin, Q.X.; Song, B.; et al. A High-Temperature Superconducting Maglev Ring Test Line Developed in Chengdu, China. IEEE Trans. Appl. Supercond. 2016, 26, 3602408. [CrossRef]

16. Wang, Y.; Chan, W.K.; Schwartz, J. Self-Protection Mechanisms in No-Insulation (RE) $\mathrm{Ba}_{2} \mathrm{Cu}_{3} \mathrm{O}_{\mathrm{x}}$ High Temperature Superconductor Pancake Coils. Supercond. Sci. Technol. 2016, 29, 45007. [CrossRef]

17. Wang, Y.W.; Weng, F.J.; Li, J.W.; Souc, J.; Gomory, F.; Zou, S.N.; Zhang, M.; Yuan, W.J. No-Insulation High-Temperature Superconductor Winding Technique for Electrical Aircraft Propulsion. IEEE Trans. Transp. Electrif. 2020, 6, 1613-1624. [CrossRef]

18. Jun, Z.; Feng, X.; Wei, C.; Yijun, D.; Jin, C.; Wenbin, T. The Study and Test for 1MW High Temperature Superconducting Motor. IEEE/CSC ESAS Eur. Supercond. News Forum 2013, 23, 6-9.

19. Gamble, B.; Snitchler, G.; MacDonald, T. Full Power Test of a 36.5 MW HTS Propulsion Motor. IEEE Trans. Appl. Supercond. 2010, 21, 1083-1088. [CrossRef]

20. Sivasubramaniam, K.; Zhang, T.; Lokhandwalla, M.; Laskaris, E.; Bray, J.; Gerstler, B.; Shah, M.; Alexander, J. Development of a High Speed HTS Generator for Airborne Applications. IEEE Trans. Appl. Supercond. 2009, 19, 1656-1661. [CrossRef]

21. Song, X.; Bührer, C.; Brutsaert, P.; Krause, J.; Ammar, A.; Wiezoreck, J.; Hansen, J.; Rebsdorf, A.V.; Dhalle, M.; Bergen, A. Designing and Basic Experimental Validation of the World's First MW-Class Direct-Drive Superconducting Wind Turbine Generator. IEEE Trans. Energy Convers. 2019, 34, 2218-2225. [CrossRef]

22. Filipenko, M.; Kühn, L.; Gleixner, T.; Thummet, M.; Lessmann, M.; Möller, D.; Böhm, M.; Schröter, A.; Häse, K.; Grundmann, J. Concept Design of a High Power Superconducting Generator for Future Hybrid-Electric Aircraft. Supercond. Sci. Technol. 2020, 33, 054002. [CrossRef]

23. Komiya, M.; Aikawa, T.; Sasa, H.; Miura, S.; Iwakuma, M.; Yoshida, T.; Sasayama, T.; Tomioka, A.; Konno, M.; Izumi, T. Design Study of $10 \mathrm{MW}$ REBCO Fully Superconducting Synchronous Generator for Electric Aircraft. IEEE Trans. Appl. Supercond. 2019, 29, 5204306. [CrossRef]

24. Seifert, W.; Ueltzen, M.; Muller, E. One-Dimensional Modelling of Thermoelectric Cooling. Phys. Status Solidi A Appl. Mat. 2002, 194, 277-290. [CrossRef]

25. Sato, K.; Okumura, H.; Yamaguchi, S. Numerical Calculations for Peltier Current Lead Designing. Cryogenics 2001, 41, 497-503. [CrossRef]

26. Xiangchun, X. On the Optimal Design of Gas-Cooled Peltier Current Leads. IEEE Trans. Appl. Supercond. 2003, 13, 48-53. [CrossRef]

27. Jeong, E.S. Optimization of Conduction-Cooled Peltier Current Leads. Cryogenics 2005, 45, 516-522. [CrossRef]

28. Chen, G.; Wang, Y.; Pi, W.; Shi, C.; Li, T.; Li, J.; Zhang, H. Experimental Investigation on 100 A-Class PCL for DC HTS Devices. IEEE Trans. Appl. Supercond. 2016, 26, 4800805. [CrossRef]

29. Michael, P.C.; Galea, C.A.; Bromberg, L. Cryogenic Current Lead Optimization Using Peltier Elements and Configurable Cooling. IEEE Trans. Appl. Supercond. 2015, 25, 4801805. [CrossRef]

30. Miyata, S.; Yoshiwara, Y.; Watanabe, H.; Yamauchi, K.; Makino, K.; Yamaguchi, S. Evaluation of Thermoelectric Performance of Peltier Current Leads Designed for Superconducting Direct-Current Transmission Cable Systems. IEEE Trans. Appl. Supercond. 2016, 26, 5401604. [CrossRef]

31. Dai, S.; Liu, M.; Ma, T.; Zhang, T.; Hu, L.; Wang, B.; Wang, Y. Experimental Study on Heat-leakage of 100 A-Class PCL with Varying Cross Section. IEEE Trans. Appl. Supercond. 2019, 29, 4800104. [CrossRef]

32. Chen, G.; Wang, Y.; Pi, W.; Kan, C.; Fu, Y.; Shi, C.; Li, T.; Li, J. Heat Leakage Analysis on Peltier Current Leads of Different Structures. IEEE Trans. Appl. Supercond. 2016, 26, 8801504. [CrossRef]

33. Liu, M.; Wang, Y.; Dai, S.; Wang, J.; Peng, C.; Chen, H.; Jiang, Z.; Hu, Y. Experimental Study on 1 kA-Class Peltier Current Lead for Superconducting DC Devices. IEEE Trans. Appl. Supercond. 2019, 29, 4802504. [CrossRef]

34. COMSOL. COMSOL Multiphysics ${ }^{\circledR}$, v.5.3. 2017. Available online: https://www.comsol.com/release/5.3 (accessed on 15 April 2021).

35. Hicks, C.R. Fundamental Concepts in the Design of Experiments, 4th ed.; Oxford University Press: Oxford, UK, 1993. 